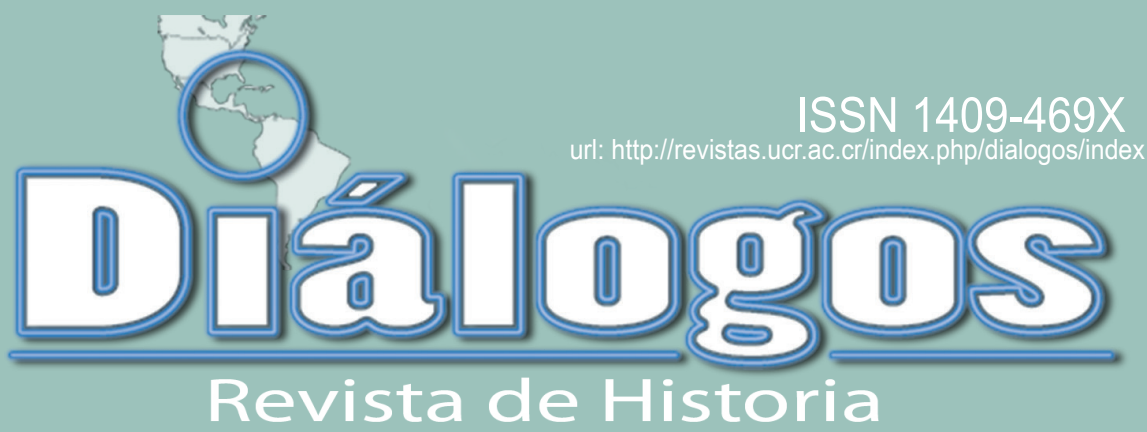

Escuela de Historia. Universidad de Costa Rica Vol. 15 No. 2 Setiembre 2014 - Enero 2015

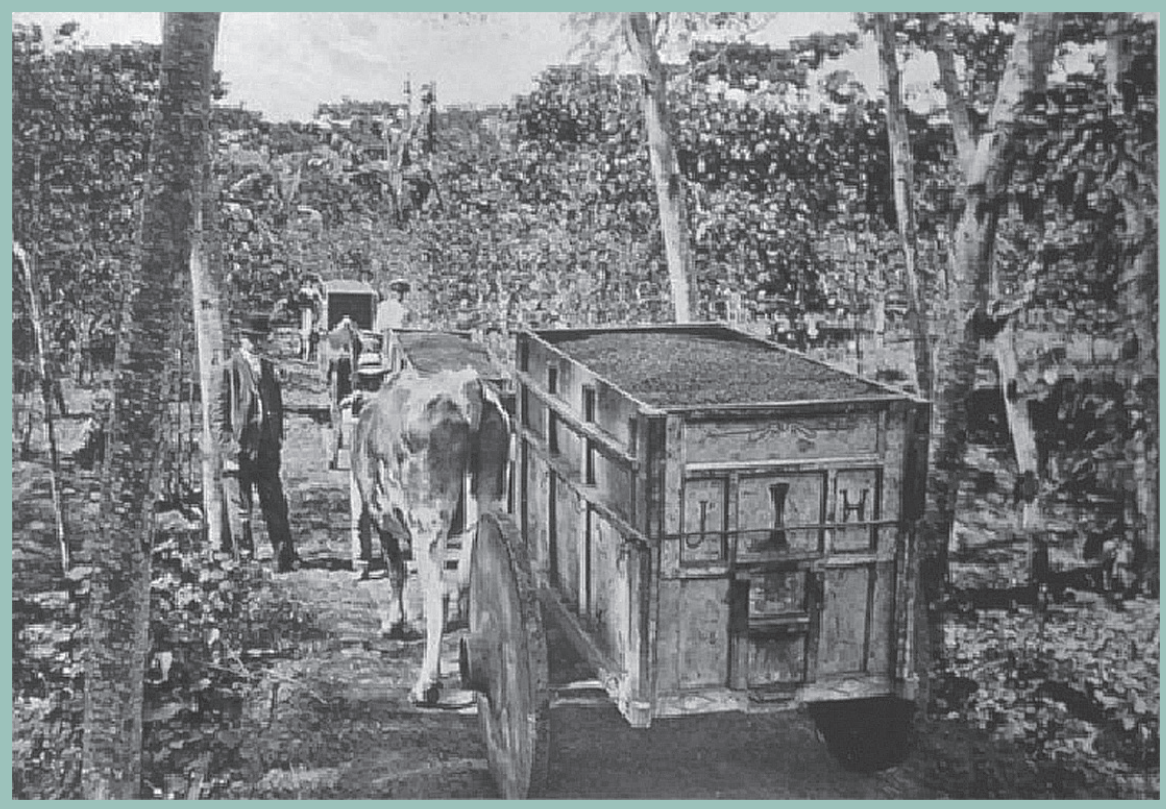

Director de la Revista: Dr. Juan José Marín Hernández juan.marinhernandez@ucr.ac.cr

Editor académico: Dr. David Díaz Arias - david.diaz@ucr.ac.cr Editor técnico: M.Sc. Marcela Quirós G. - marcela.quiros@ucr.ac.cr

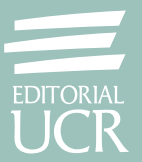




\title{
TURISMO EN EL PACÍFICO COSTARRICENSE: UN ANÁLISIS DE LA OFERTA Y DEMANDA
}

\section{TOURISM IN THE COSTA RICAN PACIFIC REGION: A SUPPLY AND DEMAND ANALYSIS}

\author{
Susan Chen Mok
}

\begin{abstract}
Palabras claves
Turismo, pacífico, oferta, demanda, actividades turísticas, recreación, Costa Rica.
\end{abstract}

\section{Keywords}

Tourism, Pacific, supply, demand, tourism activities, recreation, Costa Rica.

Fecha de recepción: 21 de marzo de 2014 - Fecha de aceptación: 25 de junio de 2014

\begin{abstract}
Resumen
En los últimos años, el turismo ha sido para el país una importante fuente de divisas, así como generador de ingresos para las comunidades rurales que poseen atractivos turísticos. Este trabajo presenta una descripción y análisis de la oferta y demanda turística existente en la región pacífica costarricense, que permite visualizar las fortalezas y las debilidades de la situación del sector turismo y proponer líneas de acción, así como dar algunas recomendaciones para contribuir a resolver las problemáticas encontradas o para profundizar en investigaciones más específicas. Se basa en datos obtenidos del Instituto Costarricense de Turismo, el Sistema Nacional de Áreas de Conservación y de otras fuentes secundarias.
\end{abstract}

\begin{abstract}
In recent years, Tourism has been an important source of income for the country as a whole as well as the specific rural communities that possess tourist attractions. We present a description and analysis of the existing tourism supply and demand in the Costa Rican Pacific region. This work permits to identify the strengths and weaknesses in the tourism trade, and proposes a line of action and provides recommendations to contribute to resolve the identified problems or recommendations for specific areas for further research. This work uses data collected by the Costa Rican Tourism Institute, the National System of Area Conservation, and other secondary sources of data.
\end{abstract}




\section{SITUACIÓN ACTUAL DEL TURISMO EN COSTA RICA}

En la pasada década, hubo un rápido crecimiento de hoteles de playa y casas de vacación en el pacifico costarricense, principalmente ligados al mercado estadounidense. Este turismo de enclave, como lo llama Cordero \& Van Duynen (2002), y residencial, respectivamente, junto con el turismo de cruceros están transformando el paisaje físico y desplazando o compitiendo por recursos con las comunidades pesqueras, agrícolas y ganaderas en la zona costera (Honey, Vargas, \& Durham, 2010, pág. 2).

Por otro lado, también encontramos una turística que explota la belleza natural del país: turismo ecológico, turismo de aventura y turismo rural comunitario; a los que de manera general se les llama "ecoturismo", el cual tiene menos impacto sobre el ambiente y el paisaje físico que el turismo de enclave y que empieza a desarrollarse centrado en una importante red de áreas silvestres protegidas, sitios públicos y privados y una infraestructura relativamente buena.

A partir de los años 90, el desarrollo del turismo empieza a generar divisas superiores a la exportación de banano y café hasta convertirse, en la década pasada, en la primera fuente de divisas del país.

De acuerdo al Plan Nacional de Turismo Sostenible de Costa Rica 2010-2016 (Instituto Costarricense de Turismo, 2010) el desempeño turístico de Costa Rica ha sido competitivo, pues se ha mantenido un flujo importante de turistas a pesar de la crisis que se vivió en los años 2008 y 2009 y que afectó el principal mercado emisor de Costa Rica.

La Figura 1 muestra el comportamiento del ingreso de turistas internacionales de 1988 a 2011. Se observa una tendencia creciente, y solamente en tres momentos se presenta un descenso: 1996, 2002 y 2009.

El porcentaje de crecimiento anual del número de turistas internacionales que ingresaron al país en el periodo 1988-2012 muestra un desempeño positivo, a excepción de los años 1996, 2002 y 2009 como puede observarse en la Figura 2.

Las tablas 1 y 2 muestran los principales indicadores turísticos de Costa Rica y su porcentaje de variación anual, los cuales reflejan el desempeño del país en esta materia del 2000 al 2009.

Este aumento en el número de turistas se refleja también en el crecimiento en la cantidad de divisas que recibe el país, con una tendencia ascendente a partir del 2002 y una leve disminución en el 2009, como se muestra en las Figuras 3 y 4. La caída en el 2009 se debe, entre otras razones, a la crisis que se vivió en los años 2008 y 2009 y que afectó de manera importante a Estados Unidos, el principal país que aporta visitantes a Costa Rica. Pero se observa, en la Figura 3, que a partir del 2009 hay un crecimiento constante y que en el 2012 se alcanza un ingreso de divisas 


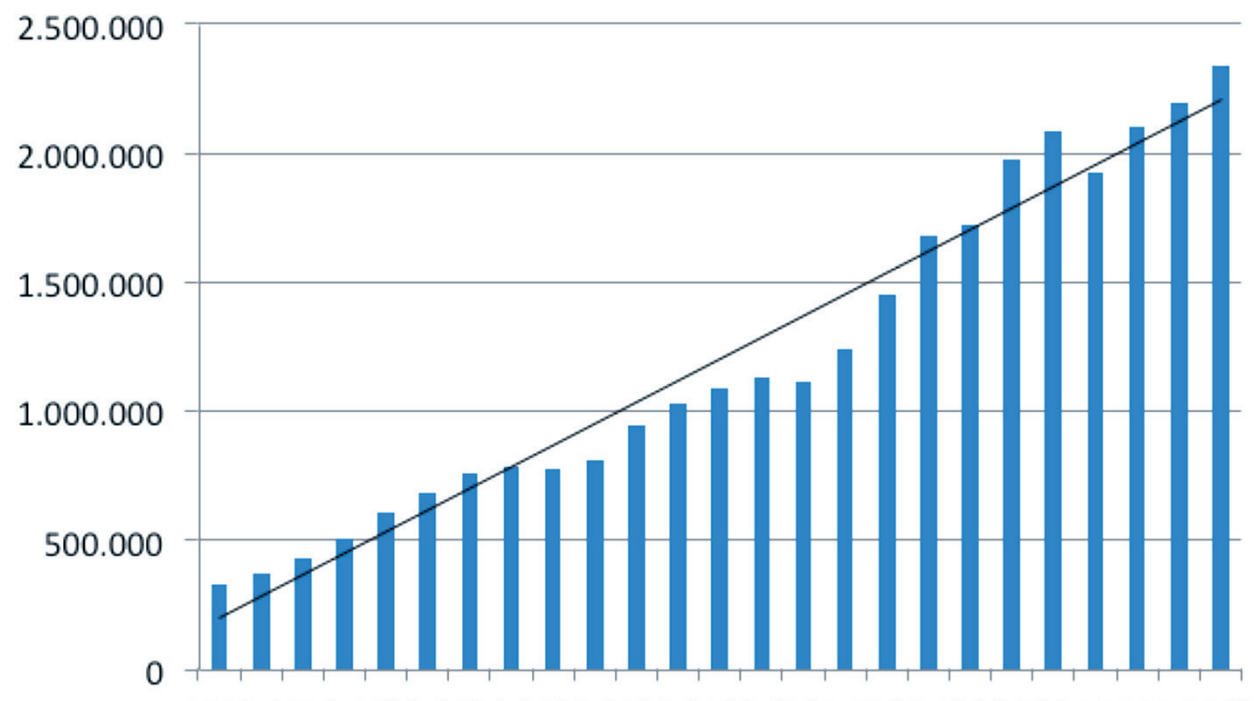

1988199019921994199619982000200220042006200820102012

Figura 1. Ingreso de turistas internacionales, 1988-2012.

Fuente: Elaboración propia con datos de los anuarios (Instituto Costarricense de Turismo, 1988-2012).

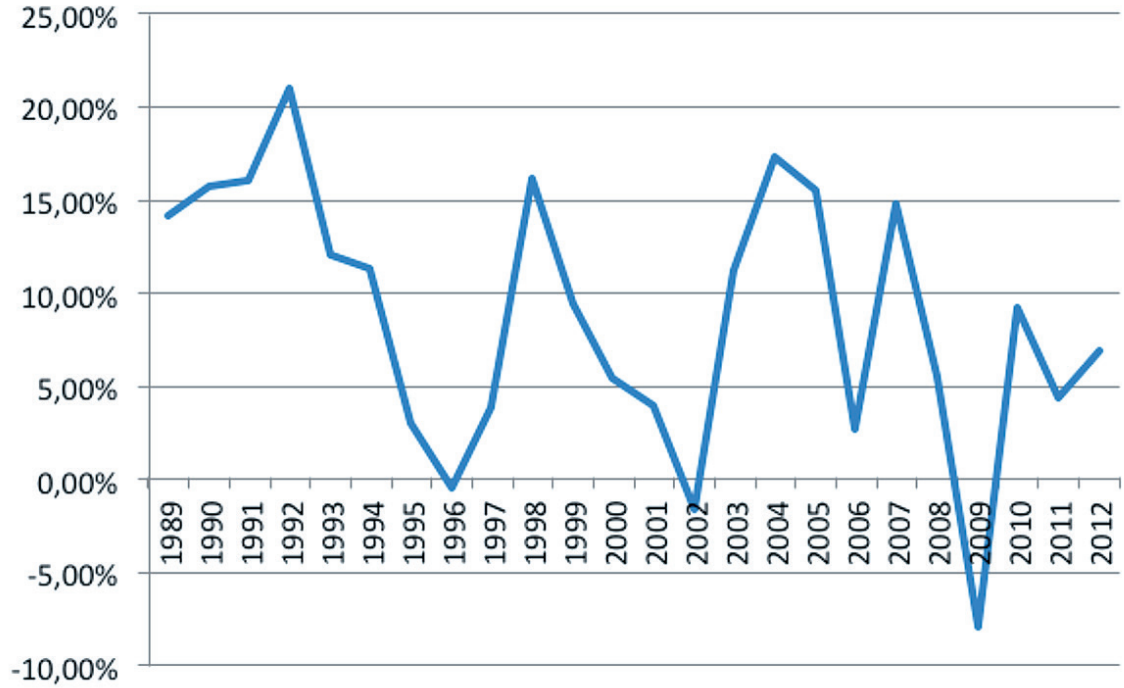

Figura 2. Porcentaje de variación anual del ingreso de turistas internacionales, 1989-2012.

Fuente: elaboración propia con los datos de los anuarios (Instituto Costarricense de Turismo, 1988-2012). 
apenas superior al del año 2008. Sin embargo, en cuanto al número de turistas, se observa en la Figura 1, que a partir del 2010 la cantidad de visitantes empieza a superar la cifra de personas que ingresaron en el año 2008. Lo anterior, muestra una recuperación de la economía en el tema del turismo y un mayor número de excursionistas que vienen al país, pero que gastan menos dinero.

\section{Tabla 1}

INDICADORES TURÍSTICOS DE COSTA RICA, 2000-2009

\begin{tabular}{|c|c|c|c|c|c|c|c|c|c|c|}
\hline INDICADOR & 2000 & 2001 & 2002 & 2003 & 2004 & 2005 & 2006 & 2007 & 2008 & 2009 \\
\hline Turistas (miles) & 1088 & 1131 & 1113 & 1239 & 1453 & 1679 & 1725 & 1980 & 2089 & 1923 \\
\hline $\begin{array}{l}\text { Divisas (millones US\$), } \\
\text { valor nominal }\end{array}$ & 1229,2 & 1095,5 & 1078 & 1199,4 & 1358,5 & 1570,1 & 1620,9 & 1927,4 & 2174,1 & 1977,8 \\
\hline $\begin{array}{l}\text { Inversión aprobada } \\
\text { (millones US\$), valor } \\
\text { nominal }\end{array}$ & 38,1 & 47,7 & 172,9 & 59,8 & 56,2 & 143,6 & 154,9 & 259,1 & 696,8 & 102,2 \\
\hline Oferta habitaciones & 29497 & 31706 & 33126 & 35003 & 36299 & 38737 & 40811 & 41340 & 41759 & 42058 \\
\hline $\begin{array}{l}\text { Cruceros (número } \\
\text { de naves) }\end{array}$ & 199 & 195 & 146 & 202 & 215 & 192 & 237 & 216 & 238 & 253 \\
\hline $\begin{array}{l}\text { Visitantes de cruceros } \\
\text { (miles) }\end{array}$ & 190 & 189 & 222 & 276 & 318 & 280 & 346 & 322 & 320 & 366 \\
\hline
\end{tabular}

Nota: Fuente: (Instituto Costarricense de Turismo, 2010, pág. 5).

Por otro lado, comparando los datos de Costa Rica con los otros países centroamericanos, incluyendo Panamá, y sin contar los turistas excursionistas que ingresan por los cruceros, Costa Rica conserva la ventaja en atracción de turistas, desde el año 2009 al 2012 (Barquero, 2013, pág. 29A). 
Tabla 2

PORCENTAJE DE VARIACIÓN ANUAL DE LOS INDICADORES TURÍSTICOS

DE COSTA RICA, 2000-2009

\begin{tabular}{|c|c|c|c|c|c|c|c|c|c|c|}
\hline INDICADOR & 2000 & 2001 & 2002 & 2003 & 2004 & 2005 & 2006 & 2007 & 2008 & 2009 \\
\hline Turistas (miles) & $5,4 \%$ & $4,0 \%$ & $-1,6 \%$ & $11,3 \%$ & $17,3 \%$ & $15,6 \%$ & $2,7 \%$ & $14,8 \%$ & $5,5 \%$ & $-7,9 \%$ \\
\hline $\begin{array}{l}\text { Divisas (millones } \\
\text { US\$) }\end{array}$ & $18,6 \%$ & $-10,9 \%$ & $-1,6 \%$ & $11,3 \%$ & $13,3 \%$ & $15,6 \%$ & $3,2 \%$ & $18,9 \%$ & $12,8 \%$ & $-9,0 \%$ \\
\hline $\begin{array}{l}\text { Inversión aprobada } \\
\text { (millones US\$) }\end{array}$ & $50,6 \%$ & $25,2 \%$ & $262,5 \%$ & $-65,4 \%$ & $-6,0 \%$ & $155,5 \%$ & $7,9 \%$ & $67,3 \%$ & $168,9 \%$ & $-85,3 \%$ \\
\hline Oferta habitaciones & $2,3 \%$ & $7,5 \%$ & $4,5 \%$ & $5,7 \%$ & $3,7 \%$ & $6,7 \%$ & $5,4 \%$ & $1,3 \%$ & $1,0 \%$ & $0,7 \%$ \\
\hline $\begin{array}{l}\text { Cruceros (número } \\
\text { de naves) }\end{array}$ & $-21,3 \%$ & $-2,0 \%$ & $-25,1 \%$ & $38,4 \%$ & $6,4 \%$ & $-10,7 \%$ & $23,4 \%$ & $-8,9 \%$ & $10,2 \%$ & $6,3 \%$ \\
\hline $\begin{array}{l}\text { Visitantes de } \\
\text { cruceros (miles) }\end{array}$ & $-19,1 \%$ & $-0,5 \%$ & $17,5 \%$ & $24,3 \%$ & $15,2 \%$ & $-11,9 \%$ & $23,6 \%$ & $-6,9 \%$ & $-0,6 \%$ & $14,4 \%$ \\
\hline
\end{tabular}

Nota: Fuente: (Instituto Costarricense de Turismo, 2010, pág. 5).

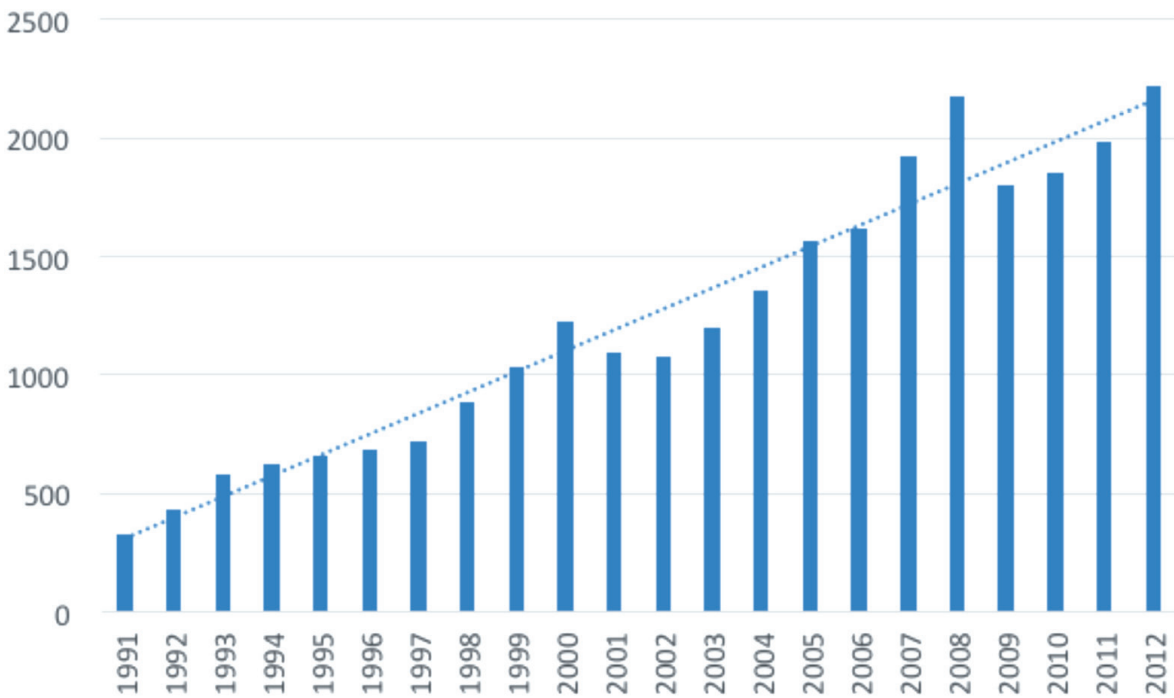

Figura 3. Divisas por turismo en millones US\$, 1991-2012.

Fuente: elaboración propia con datos de los Anuarios (Instituto Costarricense de Turismo, 1991-2012). Datos en valor nominal. 


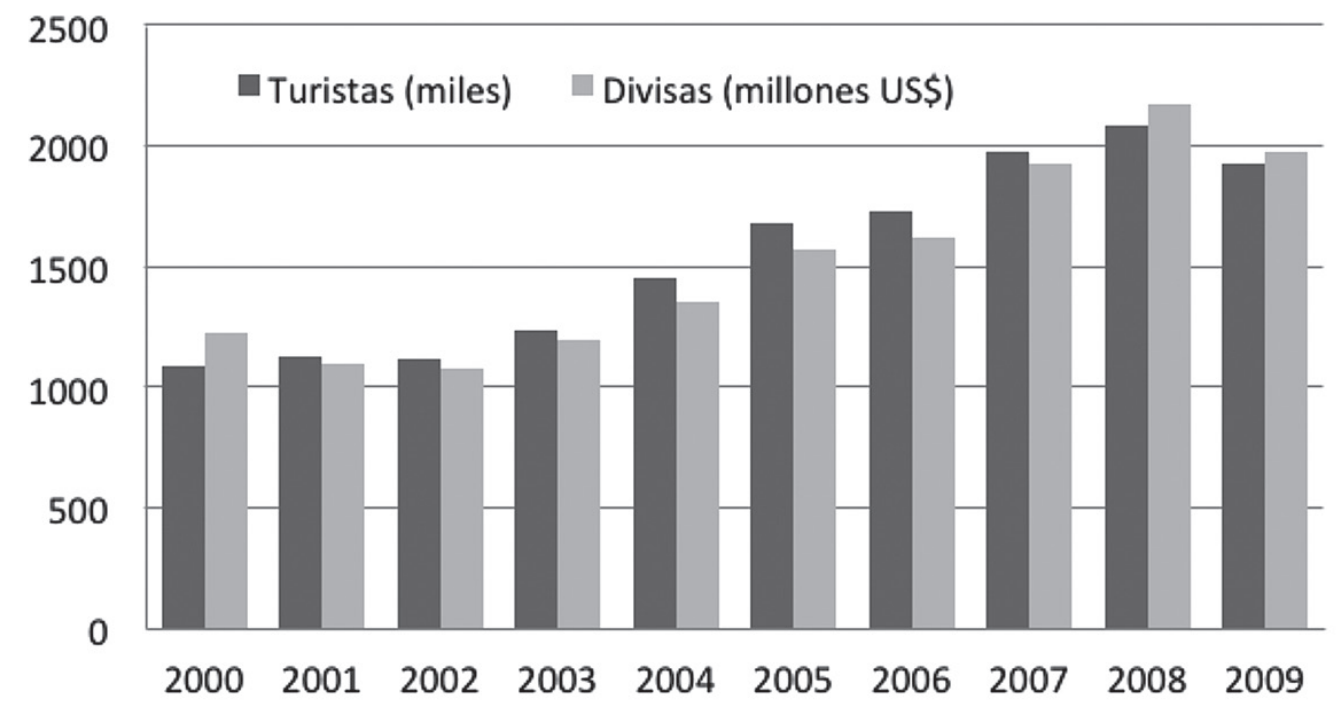

Figura 4. Ingreso de Divisas vs Ingreso de turistas, 2000-2009.

Fuente: Elaboración propia con datos del Instituto Costarricense de Turismo (2010). Datos en valor nominal.

\section{ESFUERZOS EN LA ACTUALIDAD}

El Estado Costarricense ha realizado grandes esfuerzos para fomentar el turismo internacional del país, es así como a pesar de la crisis vivida en los años 2008 y 2009 a nivel mundial, que hizo caer los indicadores de turismo de Costa Rica, se observa claramente un repunte a partir del año 2010.

Entre las actividades que se realizan para ello está el convenio entre los cinco países centroamericanos para atraer turismo internacional y movilizar entre éstos a los centroamericanos.

En el año 2012 se inicia una campaña de promoción de turismo intrarregional, en la que participan Guatemala, Honduras, El Salvador, Nicaragua, Costa Rica, Panamá y Belice. Es una campaña conjunta promovida por los Gobiernos y TACA Airlines que incluye promociones en tarifas aéreas y paquetes vacacionales (Summa, 2012). El 18 de abril del 2013 se anuncia que la aerolínea TACA, los ministerios de Turismo de cinco países centroamericanos, las cámaras de Turismo agrupadas en Fedecatur, la SICA (Secretaría de Integración Centroamericana), mayoristas de turismo y proveedores de servicios turísticos de la región impulsan el programa “Descubre Centroamérica", con una inversión de \$200.000 (La Nación, 2013).

Por otro lado, el Instituto Costarricense de Turismo ha llevado a cabo la campaña promocional "Costa Rica sin ingredientes artificiales" para promocionar al país como un destino de bellezas naturales paisajísticas y atraer a los amantes de 
la naturaleza, así como ofrecer destinos naturales para la recreación y descanso en armonía con el ambiente.

Además, este organismo gubernamental ha venido promoviendo, desde el año 2012, el turismo nacional con una campaña muy fuerte denominada "Vamos a Turistear" para que los residentes salgan a visitar los lugares turísticos del país en cualquier época del año, con ofertas especiales de las empresas hoteleras. Esta campaña es una iniciativa del Instituto en conjunto con la Cámara Nacional de Turismo Rural, la Cámara Costarricense de Hoteles y la Asociación de Operadores Turísticos (Brenes, 2013). De acuerdo con Brenes (2013), el turismo local es realizado por 2,3 millones de personas de acuerdo con datos del ICT. En promedio, cada familia realiza dos vacaciones y en cada ocasión gasta unos doscientos cincuenta mil colones.

\section{DESARROLLO DE INFRAESTRUCTURA EN EL PACÍFICO COSTARRICENSE}

De acuerdo con el estudio de Honey, Vargas \& Durham (2010, pág. 19), la Costa Pacífica se caracterizó, en la primera mitad del siglo XX, por estar conformada de pueblos rurales dedicados a la agricultura, ganadería y pesca. Las comunidades estaban aisladas, con comunicaciones pobres a los principales caminos u otros pueblos. Las exportaciones de banano se hacían a través de los puertos de Golfito y Quepos; y Puntarenas era el principal puerto de exportación e importación de otros productos. Se llegaba a Puntarenas por medio del ferrocarril y después por vehículos a través de caminos.

El ferrocarril había potenciado el turismo puntarenense de 1910 a 1940 y la finalización de la carretera Interamericana en 1946 lo fomentó aún más (Marín y Viales, 2012, pág. 185), (Chen y García, 2010, pág. 28). Entre los años 60 y 70 algunos costarricenses construyeron casas para vacacionar en la costa pacífica, aunque en ese entonces el acceso a esta zona era todavía muy limitado. Algunos pueblos solo se podían acceder por ferry, por la falta de puentes sobre algunos ríos (Honey, Vargas, y Durham, 2010, pág. 19). No obstante, ya desde 1840 las élites comerciales extranjeras fundamentales para el puerto y también nacionales comenzaron a levantar casas de ostentación. Veintitrés estructuras consideradas patrimonio en la ciudad de Puntarenas, se construyeron entre 1901 y 1950 (Marín y Viales, 2012, pág. 179)

Además, a finales de los años 60, la creación del Sistema Nacional de Áreas de Conservación colocó grandes porciones de territorio bajo protección, que incluyeron regiones extensas de la Costa Pacífica: Parque Nacional Santa Rosa, Parque Marino Las Baulas, Refugio de Vida Silvestre Tamarindo, Refugio de Vida Silvestre Camaronal, Refugio de Vida Silvestre Ostional, Parque Nacional Carara, 
Reserva Absoluta Cabo Blanco, Parque Nacional Manuel Antonio, Parque Marino Ballena y Parque Nacional Corcovado.

A partir de los años 70, la carretera Interamericana y mejores caminos comunicaron comunidades de la zona costera Guanacasteca, como playas del Coco, Conchal, Hermosa y Brasilito. En 1978 la primera sección de la construcción de la Costanera Sur abrió el acceso a Jacó y Quepos. Se continuó con la construcción de caminos y puentes hasta conectar Quepos con Dominical y la zona Sur, dando un mejor acceso a estas regiones, lo que favoreció el desarrollo turístico e inmobiliario de la zona (TT Argos, 2013, págs. VI-10). En el Pacífico Norte, a finales de los 70, el proyecto Polo Turístico Golfo de Papagayo junto con el aeropuerto Daniel Oduber en Liberia fueron parte de una estrategia gubernamental para llevar beneficios económicos a Guanacaste, mediante el turismo internacional de "resorts" (Honey, Vargas, y Durham, 2010, pág. 19) o turismo de enclave, como lo denominan Cordero y Van Duynen (2002).

En 1984, la Compañía Bananera United Fruit Company se retiró de Golfito y abandonó la producción bananera en el Pacífico, lo que dejó muchas familias sin empleo y provocó una crisis en la zona, de la cual no ha logrado recuperarse (Clare, 2005, pág. 341). En la actualidad, la población se ocupa principalmente en los sectores de agricultura y ganadería, turismo y comercio (TT Argos, 2013, págs. VI-27).

De acuerdo con Blanco (2012, pág. 289), a partir de la primera mitad de la década de 1980, el país incorpora como políticas de Estado toda una serie de medidas neoliberales impuestas por el Banco Mundial y el Fondo Monetario Internacional. Estas medidas significaron la reestructuración del aparato estatal y del sistema económico-productivo e implicaron la reducción de la planilla estatal y la privatización de empresas públicas, así como el aumentó del apoyo al sector terciario, reestructurando el sector agrícola e iniciando la apertura de la economía.

La reestructuración productiva cambió el destino de los incentivos a la producción, dando prioridad al sector agroexportador de productos no tradicionales y disminuyendo recursos a los sectores de productos tradicionales, como los granos básicos y alimentos de consumo local. Esto estimuló la incursión de muchos de estos productores en otras actividades, como las de carácter turístico, para mejorar sus ingresos y asegurar la subsistencia de sus familias. Dado lo anterior, a finales del siglo XX Guanacaste sufrió una rápida transición de una economía basada en el agro a una centrada en servicios para el turismo.

La Tabla 3 y la Figura 5 muestran el desarrollo infraestructural de 12 localidades en 5 unidades de planeamiento turístico, seleccionadas sobre la base de su desarrollo turístico y residencial, a la fecha del estudio, o según el crecimiento esperado. 
Tabla 3

TERRITORIO DEDICADO A ASENTAMIENTOS HUMANOS Y TURISMO, COSTA PACÍFICA, 1980-2005

\begin{tabular}{|c|c|c|c|c|}
\hline $\begin{array}{c}\text { UNIDAD DE PLANEAMIENTO } \\
\text { TURÍSTICO }\end{array}$ & $\begin{array}{l}\text { UBICACIÓN DE LOS } \\
\text { ESTUDIOS DE CASO }\end{array}$ & $\begin{array}{l}1980 \\
(\mathrm{HA})\end{array}$ & $\begin{array}{l}1998 \\
(\mathrm{HA})\end{array}$ & $\begin{array}{l}2005 \\
(\mathrm{HA})\end{array}$ \\
\hline \multirow{3}{*}{ Guanacaste Norte } & Papagayo-El Coco & 62,38 & 434,85 & 726,79 \\
\hline & Potrero-Flamingo-Brasilito & 31,05 & 266,67 & 418,24 \\
\hline & Playa Grande-Tamarindo & 22,47 & 246,85 & 837,61 \\
\hline \multirow{3}{*}{ Guanacaste Sur } & Sámara-Punta Islita & 56,94 & 224,77 & 544,34 \\
\hline & Malpaís-Montezuma & 13,15 & 7,52 & 32,24 \\
\hline & Paquera & 12,77 & 11,23 & 23,16 \\
\hline Puntarenas e islas del Golfo & Puntarenas-Caldera & 726,38 & 1291,03 & 1724,84 \\
\hline \multirow{2}{*}{ Pacífico Central } & Herradura-Jacó & 78,98 & 268,34 & 415,92 \\
\hline & Quepos-Manuel Antonio & 190,98 & 301,5 & 297,46 \\
\hline \multirow{3}{*}{ Pacífico Sur } & Dominical-Tortuga & 10,56 & 50,05 & 43,98 \\
\hline & Golfito & 184,43 & 200,05 & 215,52 \\
\hline & Puerto Jiménez & 25,67 & 88,54 & 101,96 \\
\hline
\end{tabular}

Nota: Fuente: Elaboración propia con datos TT Argos 2009 citado por Honey, Vargas y Durham (2010, pág. 22). 


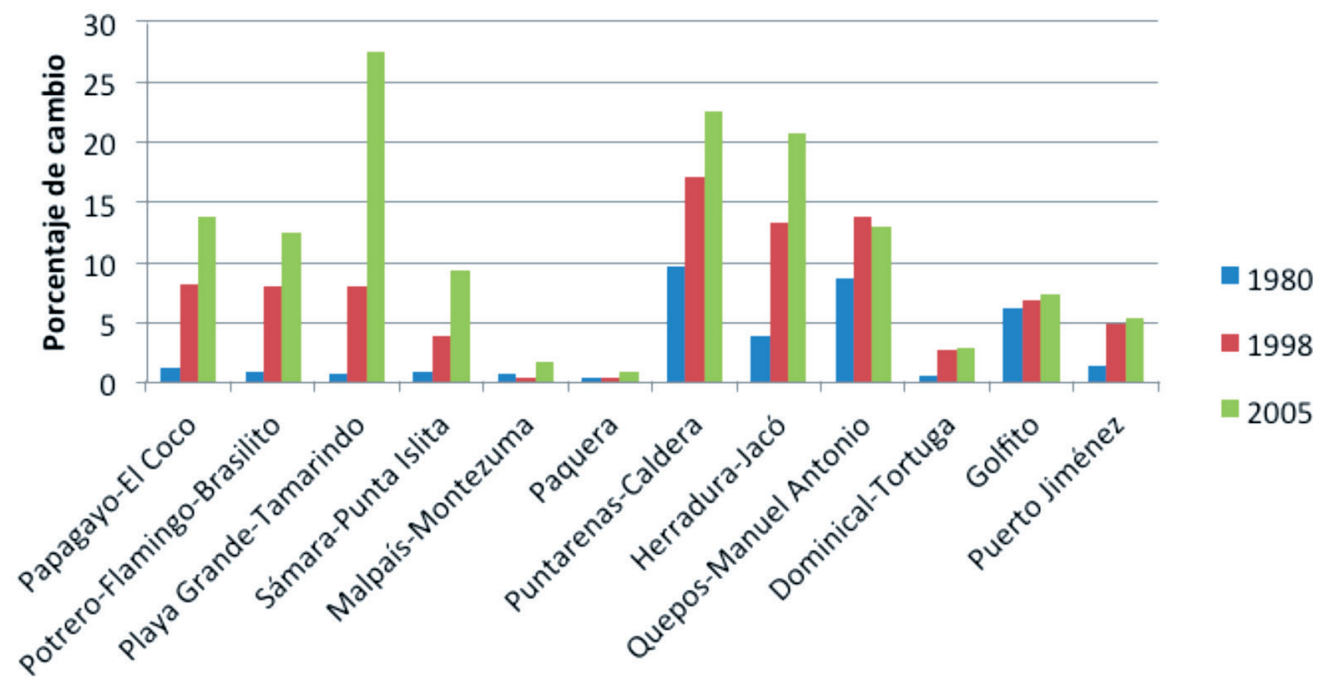

Figura 5. Porcentaje de cambio en el uso del suelo para asentamiento humano y turismo.

Fuente: Elaboración propia con datos TT Argos 2009 citado por Honey, Vargas y Durham (2010, pág. 22).

Los datos de la Tabla 3 y Figura 5 muestran el crecimiento en el cambio del uso del suelo de las localidades Playa Grande-Tamarindo, Puntarenas-Caldera y Herradura-Jacó, lugares donde se ha visto un desarrollo significativo de infraestructura turística, así como de vivienda, este último por el aumento de residenciales producto del desarrollo turístico de la zona.

Se observa cómo Playa Grande-Tamarino pasa de menos del 1\% del uso de suelo dedicado a asentamientos humanos y turismo en 1980 a un $27,5 \%$, en el 2005. Esto se debió al crecimiento de inversiones en hoteles, casas de vacación, condominios y negocios turísticos. Lo mismo se observa en Puntarenas-Caldera y Herradura-Jacó, así como en el resto de las localidades de la costa de Guanacaste, donde en el año 1980 el porcentaje de uso de suelo para asentamientos humanos y turismo es muy bajo y luego aumenta para en el año 2005.

Este desarrollo contrasta con las localidades de Malpaís-Montezuma, Paquera, Dominical-Tortuga, Golfito y Puerto Jiménez, donde el cambio en el uso de suelo es muy bajo. En los casos de las zonas del Pacífico Sur (Dominical-Tortuga, Golfito y Puerto Jiménez), este poco incremento se debe a que grandes territorios están bajo protección, además de carecer de infraestructura (caminos pavimentados, aeropuerto internacional, electrificación rural, etc.) requeridos para un turismo de gran escala y la implementación de proyectos residenciales.

Del 2005 al 2007, 26 de los 48 distritos a lo largo de la Costa Pacífica representaron el 92,3\% de las nuevas construcciones costeras. En Liberia, Tamarindo, Sardinal y Jacó la construcción se incrementó el 12,2\%, con respecto al porcentaje 
de todas las nuevas construcciones a nivel nacional, y el 49,8\% del total de construcciones de la Costa Pacífica. Aparte de las áreas protegidas, pocas zonas de la Costa Pacífica permanecen intactas, sin verse afectadas por este desarrollo de las bienes raíces (Honey, Vargas, y Durham, 2010, pág. 50).

Los distritos del Pacífico Central y Norte son los que recibieron mayor inversión extranjera en bienes raíces a nivel nacional, entre los años del 2004 al 2007, entre ellos encontramos: Santa Cruz, Puntarenas, Carrillo, Golfito, Nicoya, Tilarán, Garabito, Aguirre, Pérez Zeledón y Bagaces, en ese orden de mayor a menor. Se aclara que estas inversiones extranjeras no sólo corresponden al desarrollo de hoteles costeros como: Los Sueños Marriott, Reserva Conchal, Hacienda Pinilla, JW Marriott, Four Season, Hilton y Hyatt; hay también una tendencia creciente hacia la compra por parte de extranjeros de propiedades para uso de viviendas, tierras, condominios, villas, establecimientos comerciales, entre otros.

Adicionalmente, datos del 2006 y 2007 informan que los cantones de Osa y Golfito, pertenecientes al Pacífico Sur se encuentran entre de mayor incremento en la construcción de obras nuevas de infraestructura (TT Argos, 2013, págs. VI-11) durante estos años.

\section{EVOLUCIÓN DE LA DEMANDA DE ACTIVIDADES TURÍSTICAS}

El siguiente gráfico muestra la visitación a las áreas silvestres protegidas del país, desagregados por región. Como se puede observar, las áreas del Pacífico tienen un crecimiento constante, con una caída en el número de visitas en el año 2005 , pero que se recupera y continúa a la alza. A diferencia de las otras regiones que muestran varios años con bajas en el nivel de visitación. Se observa que el Valle Central tiene cuatro bajas en el período que corresponde a los años 2003, 2006, 2008 y 2009. El Caribe tiene dos bajas en los años 2005 y 2009 y el Norte presenta un decrecimiento en la visitación en los años 2006, 2007 y 2009. Lo anterior, demuestra un aumento del gusto de los turistas por visitar zonas de la región Pacífica, superando al Valle Central a partir del año 2006.

Es importante notar que, a partir del año 2010, el Sistema Nacional de Áreas de Conservación cambió la forma de administración de las áreas silvestres protegidas de Unidades de Planeamiento a Áreas de Conservación. En la Figura 6 se muestran cuatros grandes regiones. Se estableció para el estudio que el Pacífico correspondía a las unidades de planeamiento de Guanacaste Norte, Guanacaste Sur, Pacífico Medio, Pacífico Sur, Puntarenas e islas del Golfo y Monteverde. El Caribe corresponde a las unidades de Planeamiento Caribe Norte y Caribe Sur. La región Norte corresponde a las Llanuras del Norte, y por último el Valle Central es la unidad de planeamiento del mismo nombre. 


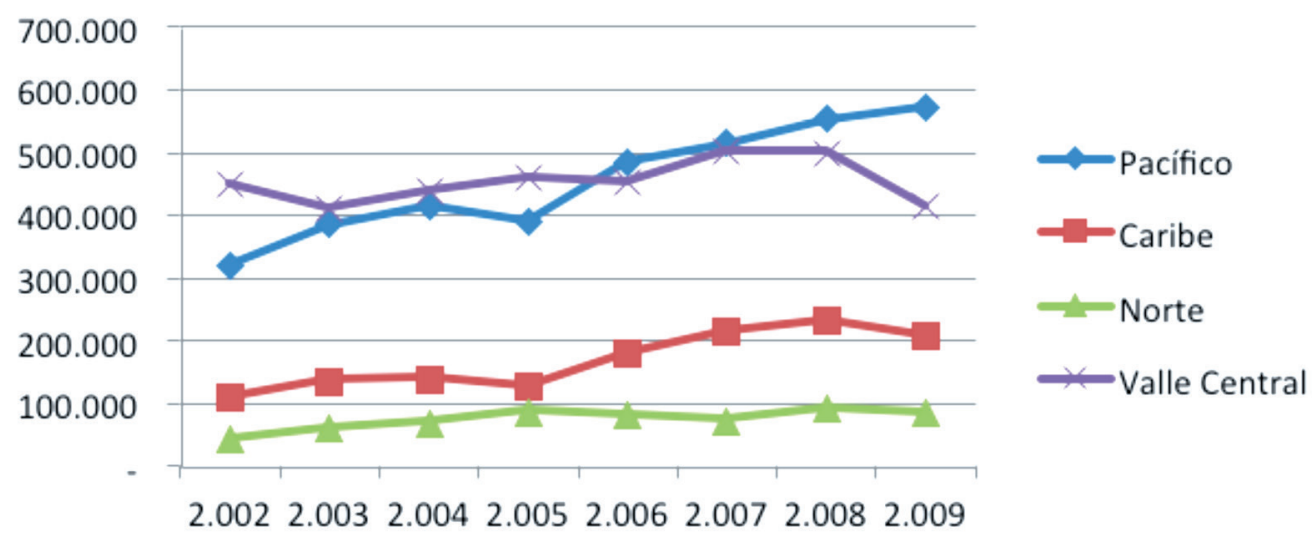

Figura 6. Visitas a áreas silvestres protegidas, 2002-2009.

Fuente: elaboración propia con datos del Sistema Nacional de Áreas de Conservación (2011).

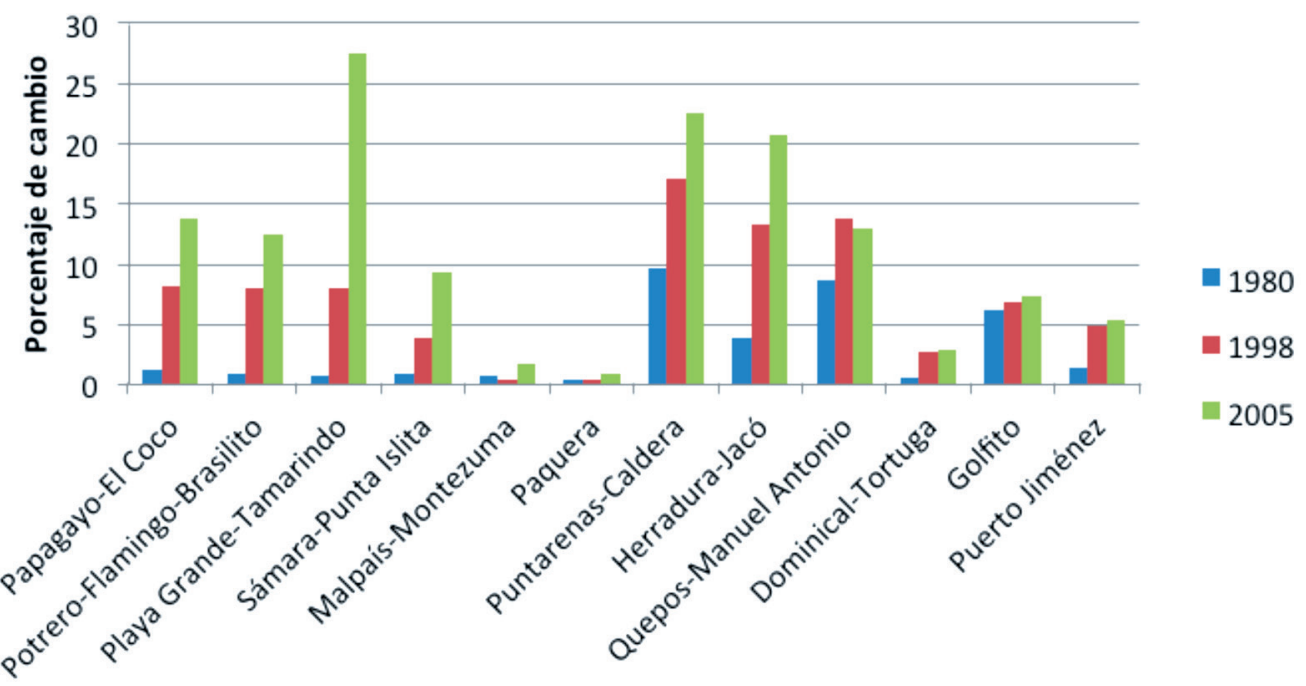

Figura 7. Visitación a las áreas silvestres protegidas de Costa Rica, 2010-2012.

Fuente: Elaboración propia con datos de Pavlotzky y Rojas (2010), (2011) y (2012).

La Figura 7 corresponde al periodo que abarcan los años del 2010 al 2012, durante el cual se modificó la denominación de las zonas indicada. En este caso, la región Pacífico corresponde a las áreas de conservación que se listan en la Tabla 7.

La Figura 7 muestra la visitación a las áreas silvestres protegidas de los 2010 al 2012 y claramente se observa que la del Pacífico y la del Valle Central van en aumento, esta última siempre por debajo de la cifra presentada en el Pacífico. La 
visitación de las otras dos regiones Caribe y Huetar Norte aumenta en el 2011 y vuelve a disminuir en el 2012.

Hay que hacer notar en este punto que la región Pacífico cubre una mayor área del territorio costarricense, por lo que la comparación tal vez no sea justa. Pero lo que sí se puede decir es que hay un mayor gusto de los turistas por visitar las zonas del Pacífico, y entre éstas se demuestra una preferencia por las áreas del Pacífico Central, como se muestra en la Figura 8.

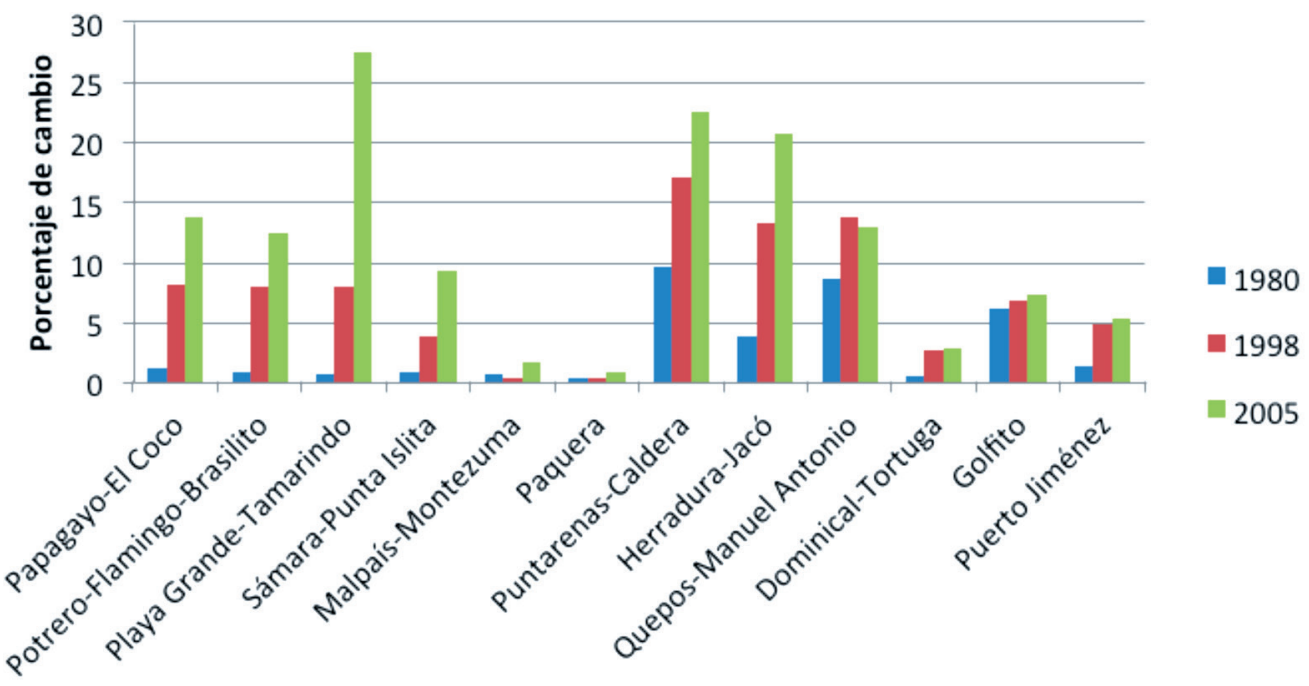

Figura 8. Visitación a las áreas protegidas del Pacífico de Costa Rica por área de conservación, 2010-2012.

Fuente: Elaboración propia con datos de Pavlotzky y Rojas (2010), (2011) y (2012).

Los acrónimos utilizados en la Figura 8 se encuentran detallados en la Tabla 7 en el que se lista las áreas silvestres protegidas de las áreas de conservación de la región pacífica.

Sin embargo, la baja visitación a la región del Pacífico Sur no es sólo a las áreas silvestres protegidas, sino también a toda la zona en general, como lo manifiestan los líderes comunales y actores locales del sector Sur del país.

Para los costarricenses (TT Argos, 2013, págs. VI-46), el Pacífico Sur se percibe como un lugar inhóspito, con sólo dos centros de atracción conocidos: Paso Canoas (frontera con Panamá) y el puerto bananero de Golfito. Los viajes al Pacífico Sur fueron motivados por la oportunidad de comprar productos de consumo a menor precio en Paso Canoas y el puerto bananero de Golfito. Las visitas a éste último lugar se promovieron aún más con la creación del Depósito Libre de Golfito, permitiendo a las familias costarricenses comprar artículos sin pagar los impuestos 
nacionales. No fue sino hasta que se mejoró la carretera costanera y el se aumentó el turismo basado en la naturaleza, que se potenció el Pacífico Sur como destino ecoturístico, y actualmente se ofrecen nuevas actividades como la observación de ballenas, delfines y el buceo.

A pesar de este nuevo auge en actividades ecoturísticas en la zona, los líderes y actores locales manifiestan que la zona del Pacífico Sur tiene poca afluencia de turistas por las limitaciones en infraestructura y servicios, además de que el acceso a los parques nacionales es restringido (Jara, 2012). Para ello, el ICT presentó el Plan Nacional de Desarrollo Turístico para el Pacífico Sur, con el objetivo de diagnosticar las condiciones de la región en materia turística y promover el turismo vivencial, buscando que el visitante interactúe con las costumbres locales.

\section{TURISMO DE CRUCEROS}

La Figura 9 muestra el ingreso de excursionistas de cruceros a los puertos del Pacífico. Se observa que de 1997 al 2000 hay un crecimiento del número de visitantes. A partir del 2001 hay una disminución considerable que coincide con el repunte de ingreso de excursionistas en el Caribe. A partir del 2002 en adelante hay una tendencia creciente, la cual siempre es inferior al número que ingresa en el Caribe (Chen, 2013, pág. 71), y en el 2012 la cifra supera el número de turistas que ingresaron en el año 1997 a estos puertos, además de sobrepasar las visitas al Caribe, como puede verse en la Figura 10.

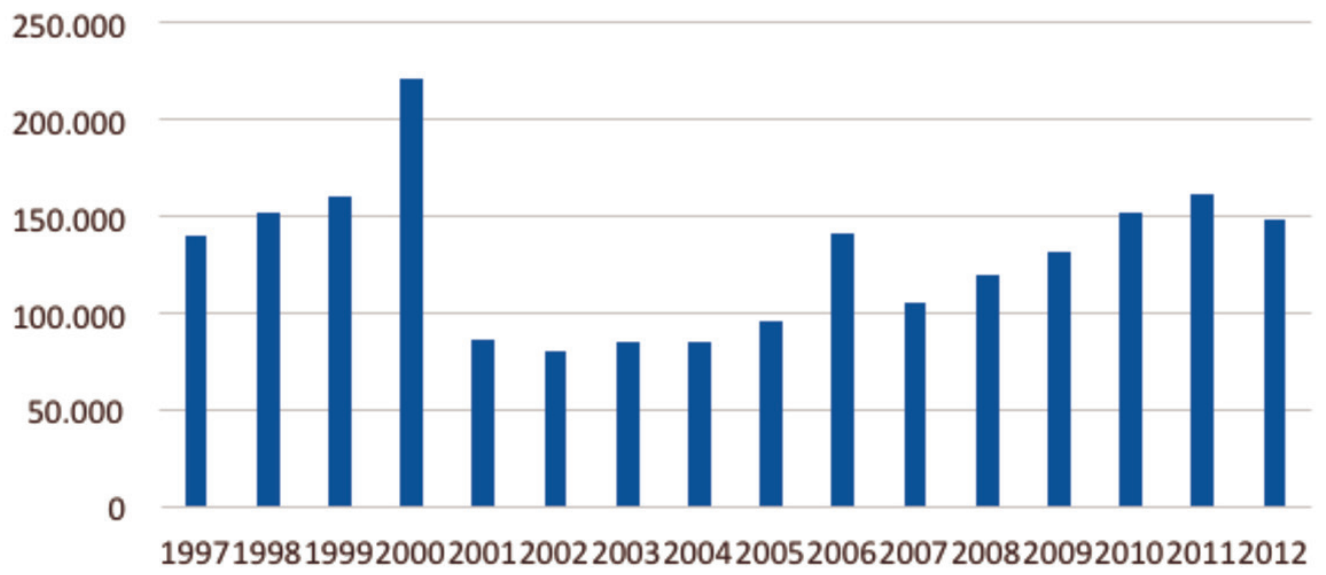

Figura 9. Ingreso de excursionistas por los puertos: Puntarenas, Caldera y Golfito.

Fuente: elaboración propia con datos de los Anuarios del Instituto Costarricense de Turismo (Instituto Costarricense de Turismo, 1988-2012). 


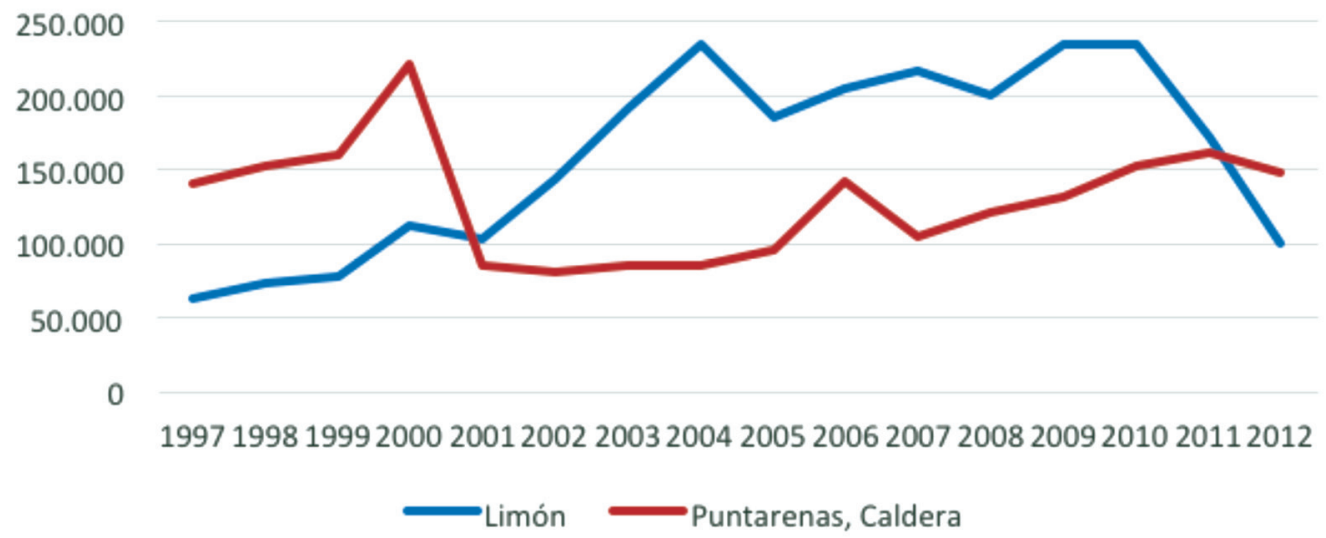

Figura 10. Llegada de turistas por crucero según puerto, 1997-2012.

Fuente: Elaboración propia con datos de los Anuarios del Instituto Costarricense de Turismo (1988-2012).

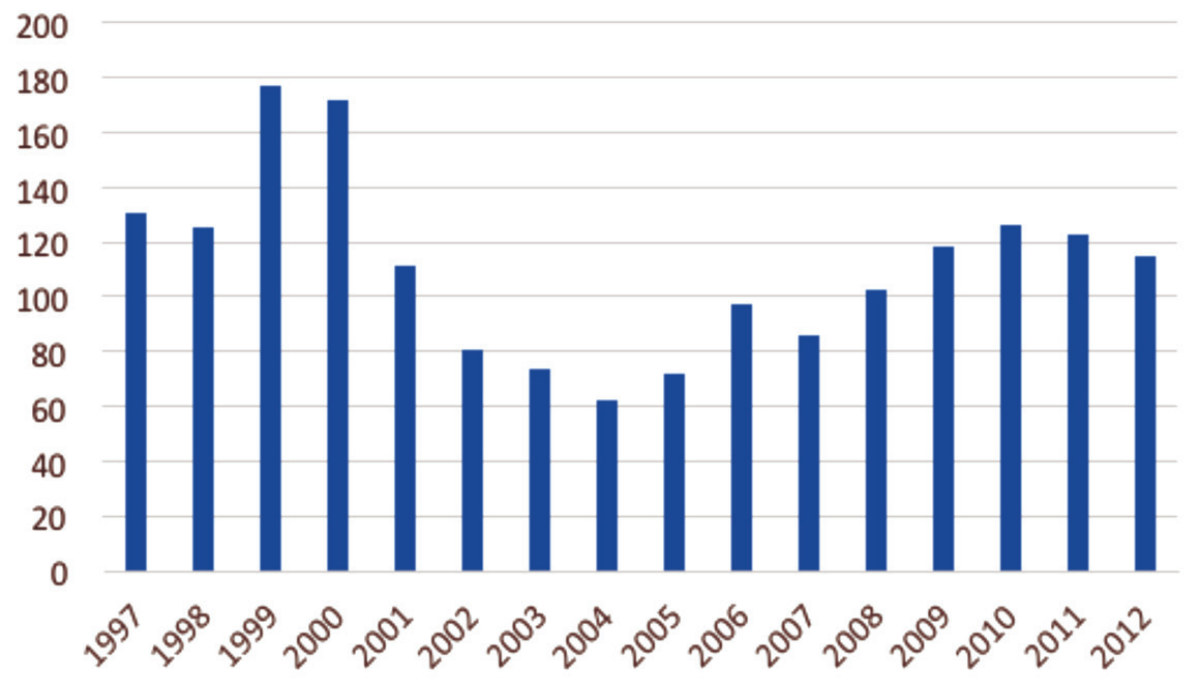

Figura 11. Llegada de cruceros a los puertos Puntarenas, Caldera y Golfito, 1997-2012. Fuente: elaboración propia con datos de los Anuarios del (Instituto Costarricense de Turismo, 1988-2012). (Instituto Costarricense de Turismo, 1988-2012)

La Figura 11 muestra el número de cruceros que atracan en los puertos de Puntarenas, Caldera y Golfito. Se observa una tendencia creciente hasta el año 2000, a partir del cual se disminuye hasta el año 2004, durante el cual la cifra alcanza los 62 cruceros. Luego inicia nuevamente la tendencia a la alza, aumentando el número de cruceros que atracan en los puertos del Pacífico de 62 en el año 2004 a 123 en el año 2011. Este crecimiento del número de cruceros también se refleja en el aumento de los excursionistas que llegan a estos puertos, como se puede observar 
en el gráfico anterior, sin embargo, al año 2011, la cantidad de cruceros no supera la cantidad que ingresó en el año 1997.

Sin embargo, a pesar de los datos de ingresos de excursionistas de cruceros a los puertos del Pacífico, la mayoría de ellos vienen con paquetes de tours comprados a bordo, los cuales son manejados por grandes operadores, y con contratos adquiridos mediante las líneas de cruceros, los cuales reciben un gran porcentaje de los honorarios (Honey, Vargas y Durham, 2010, pág. 62). Estos paquetes de tours incluyen otros sitios fuera de Puntarenas, por lo que el beneficio mayor de este turismo no se queda en la ciudad portuaria, ni sus alrededores (Mora, 2013, pág. 109). A pesar de esto, los pequeños comerciantes del puerto (restaurantes, artesanías, vendedores ambulantes, etc.) consideran que sus ingresos aumentan moderadamente y que lo que más se venden son productos de licor, tabaco y artesanías como recuerdo del viaje. Los productos alimenticios no se venden debido a que el crucero incluye la alimentación (Mora, 2013, pág. 101).

Caldera ha sido un puerto utilizado, principalmente, para carga, pero también ha servido para el atraco de cruceros. Sin embargo, la zona se encuentra un poco alejada de centros de poblado que ofrezcan los servicios necesarios requeridos por los turistas. Los cruceros llegan y sus ocupantes ingresan inmediatamente a los buses que los conducirán a los tours previamente comprados (Honey, Vargas y Durham, 2010, pág. 62).

El puerto Golfito no está dentro del último Plan Nacional de Desarrollo para la Región del Pacífico, como destino para turismo de cruceros. No obstante, Golfito ha recibido cruceros, pero no ha sido un destino importante para estos (Honey, Vargas y Durham, 2010, pág. 62).

De acuerdo con Honey, Vargas y Durham (2010, pág. 63), el turismo de cruceros ha tenido un impacto económico positivo muy bajo para Puntarenas y Caldera y para Costa Rica en general.

\section{ACTIVIDADES TURÍSTICAS}

De acuerdo con el Plan Nacional de Turismo Sostenible, las actividades que realizan los turistas durante la estadía en el país se muestran en la Tabla 4.

Es importante observar en este cuadro la diversificación de los gustos de los turistas, al considerar una amplia gama de actividades turísticas no solo de sol y playa. Esto a diferencia del período que va de 1950 a 1970, en el cual Puntarenas se consolida como un destino turístico para el visitante nacional e internacional (condición que se mantuvo por un período corto, al mejorar el acceso a otros sitios poco intervenidos por el hombre como Jacó y Playas del Coco), época durante 
la cual los gustos de los turistas estaban orientados al sol y las playas, y que el Gobierno aprovechó para fomentar el crecimiento económico con pocas inversiones mediante el diseño de estrategias de comercialización más eficientes, con poca diversificación de la oferta turística. De 1970 a 1995 el desarrollo del turismo se basó en el crecimiento de la actividad, pero no en la diversificación (Marín y Viales, 2012, pág. 188).

Tabla 4

ACTIVIDADES QUE REALIZAN LOS TURISTAS, 2006-2010

\begin{tabular}{|c|c|}
\hline ACTIVIDAD TURÍSTICA & PROMEDIO 2006-2010 \\
\hline Sol y playa & $77 \%$ \\
\hline Observación de flora y fauna & $52 \%$ \\
\hline Caminatas & $45 \%$ \\
\hline Compras & $37 \%$ \\
\hline Observación de aves & $35 \%$ \\
\hline Canopy & $32 \%$ \\
\hline Aguas termales & $26 \%$ \\
\hline Visita a volcanes & $25 \%$ \\
\hline Surf & $20 \%$ \\
\hline Snorkel & $16 \%$ \\
\hline Visita a familiares & $12 \%$ \\
\hline Aprender español & $11.6 \%$ \\
\hline Cabalgatas & $11 \%$ \\
\hline Museos y teatros & $11 \%$ \\
\hline Rápidos & $9 \%$ \\
\hline Kayak & $6 \%$ \\
\hline Buceo & $5 \%$ \\
\hline Pesca & $5 \%$ \\
\hline Puentes colgantes & $5 \%$ \\
\hline Delfines y ballenas & $5 \%$ \\
\hline Luna de miel & $5 \%$ \\
\hline Cuadraciclos & $3 \%$ \\
\hline Visita comunidad rural & $3 \%$ \\
\hline Ciclismo de montaña & $2 \%$ \\
\hline
\end{tabular}

Nota: Fuente: (Instituto Costarricense de Turismo, 2010, pág. 14) 
Según Vargas (2003, pág. 5), durante este período el turismo se concentró en el Valle Central con destinos específicos en el centro del país, como los volcanes Irazú y Poás; y el Pacífico Central, hacia Puntarenas, y en menor medida, Jacó. Entre las razones de estas preferencias se indica la inexistencia de una distribución vial adecuada, escasa cobertura de infraestructura de servicios para atender al turista en zonas con potencial turístico, carencia de visión empresarial e inexistencia de políticas gubernamentales bien planificadas para considerar el desarrollo de la actividad.

En el período indicado en el cuadro, 2006-2010, se observa que el visitante actual demanda nuevas actividades turísticas, siempre relacionadas con la naturaleza, pero ya no sólo "el sol y la playa".

Villalobos, Galdeano y Tolón (2009, pág. 76) realizan un análisis de la intención de demanda del turista internacional por "turismo naturaleza", según variables socio-demográficas y condición de viaje. El estudio del Instituto Costarricense de Turismo se sustenta en datos de la Encuesta Aérea del primer trimestre del año 2007, aplicada a turistas no residentes mayores de 18 años que salieron del aeropuerto Juan Santamaría y comprende las modalidades: caminata por senderos, visita a volcanes, observación de flora y fauna, observación de aves y canopy. Se encontró que las condiciones: viajar con familia, en pareja y procedencia del turista tienen potencial influencia favorable en la intención de demanda en la mayor parte de esas actividades. Los resultados permiten esbozar una estrategia que orienta las políticas y acciones en materia de turismo naturaleza en el país. Entre sus conclusiones y recomendaciones se encuentran las siguientes (p.97):

- Los atributos de la naturaleza nacional no parecen ser suficientes para el posicionamiento turístico del país.

- El canopy, la observación de aves, la visita a volcanes y la caminata por senderos conforman el conjunto de actividades de turismo naturaleza, con más alta probabilidad de ser demandadas por los turistas que arriban al país en familia, en pareja o con estudios superiores a maestría. A pesar del significativo porcentaje de tales tipos de turistas, el país requiere de una estrategia que posicione en esos segmentos del mercado al turismo naturaleza nacional.

- Los turistas de Latinoamérica y el Caribe muestran un elevado designio por los volcanes, el de Europa aspira a observar flora y fauna en general, y aves en particular. Una estrategia de las empresas vinculadas a tales actividades, sería informarse acerca de las preferencias de dichos turistas, para ofrecerles paquetes a la medida. 
- $\quad$ Entre otros factores que podrían estar repercutiendo negativamente en las ventajas del turismo naturaleza, están: distancia, tarifas, manejo del ambiente y la biodiversidad, seguridad, información, infraestructura, transporte y atención al turista. Si se tratara de parques y reservas naturales, se refuerza tal tendencia.

- Para visitantes de 50 o más años, el país ha de gestar una oferta de tales actividades apropiadas en términos de espacios, condiciones y oportunidades.

- $\quad$ Se requiere una estrategia que incite en el segmento femenino la realización de al menos una actividad de turismo naturaleza, impulsa de manera directa la intención de demanda por flora/fauna y volcanes, mientras influye favorablemente en la demanda de caminata por senderos, canopy y observación de aves a través de las familias, las parejas, los casados (as) y amigos (as). La mujer constituye un eje generador de efectos multiplicadores a través de tales núcleos de mercado.

- Se requiere mejorar las condiciones y oportunidades de oferta, en los diferentes ámbitos donde esta se genera. Tal es el caso de las reservas y parques nacionales, donde es posible para el turista realizar al menos una de las actividades en cuestión. El 33\% de los entrevistados apuntó no visitar esas áreas, de manera que existe un potencial para favorecer el desarrollo de tales actividades. Además, el 34,5\% de los turistas que 'ya han estado' en el país, podría darse la oportunidad de realizar al menos una actividad de turismo naturaleza; quizá aquella que no había hecho en su viaje precedente.

\section{OFERTA TURÍSTICA EN LA REGIÓN DEL PACÍFICO COSTARRICENSE}

En los gráficos siguientes se puede observar la evolución de la cantidad de empresas con declaratoria turística en Puntarenas y Guanacaste, considerando que estas dos provincias cubren el Pacífico costarricense.

En el siguiente cuadro se muestra la cantidad de habitaciones con declaratoria turística que se ofrece en estas dos provincias, no aparecen los datos de los años 2006 al 2008 debido a que no se encontraban desagregados por provincia, como en el resto de los años. Se puede observar que hay una tendencia de aumento con pequeñas bajas en los años 1998, 2002 y 2011 para Puntarenas. Para Guanacaste la tendencia es creciente con una alza significativa de la oferta habitacional a partir 


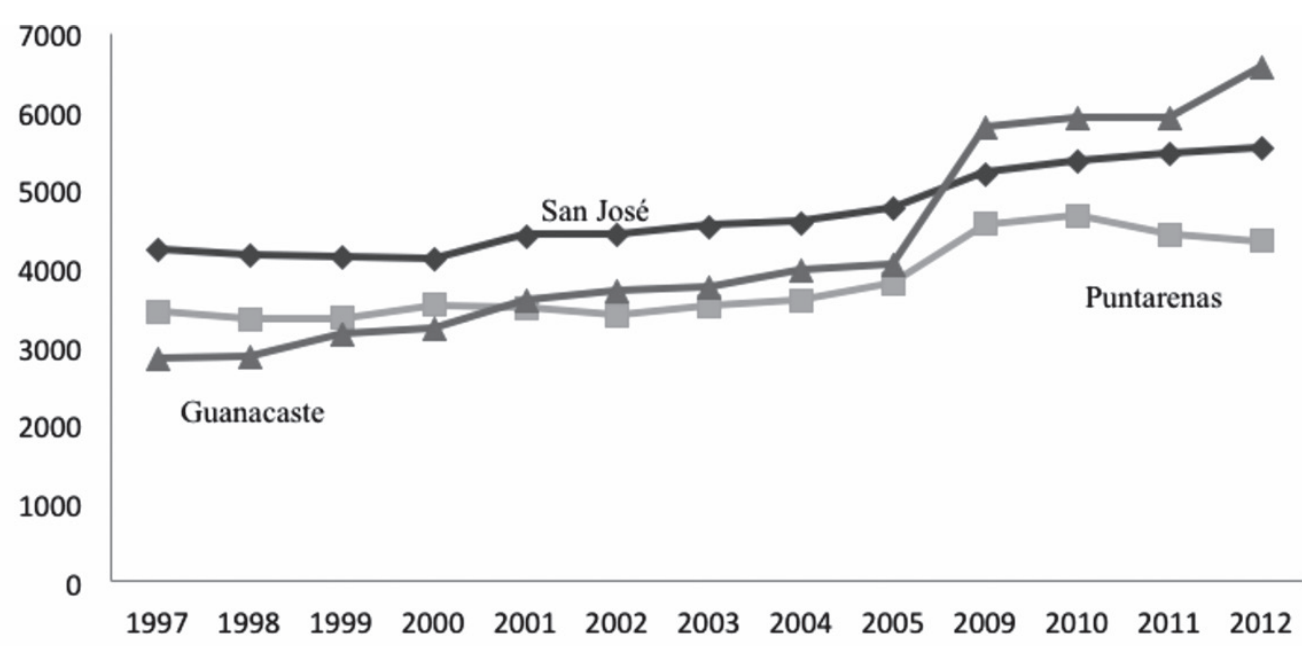

Figura 12. Gráfico 12. Habitaciones con declaratoria turística en San José, Puntarenas y Guanacaste, 1997-2012.

Fuente: Elaboración propia con datos de los Anuarios del (Instituto Costarricense de Turismo, 1988-2012).

del año 2005. En el caso de San José, la capital, a partir del año 1997 y hasta el año 2000 la tendencia es decreciente, a partir de este año inicia un incremento leve pero constante hasta el año 2012.

Solo se grafican los datos para estas tres provincias, Puntarenas y Guanacaste, que constituyen entre ambas las zonas del Pacífico costarricense, y se contrastan con la capital San José, para comparar su evolución. Estas tres provincias contienen el mayor número de oferta habitacional del país para el período de estudio. Y se observa que la oferta habitacional de Guanacaste es superior a la oferta de Puntarenas a partir del año 2001, la cual además supera a la oferta de San José a partir del año 2009, según la Figura 12.

Aquí podemos hacer una desagregación muy general de tal forma que se consideren los datos de Guanacaste como los datos para el Pacífico Norte. Y los datos de Puntarenas para el Pacífico Central y Sur.

Además de la oferta habitacional, se puede observar el comportamiento a lo largo de los años de la oferta de otros servicios, con declaratoria turística, como: agencias de viajes, transporte acuático, empresas gastronómicas, alquiler de vehículos y empresas de hospedaje. Se demuestra que las empresas de hospedaje presentan la mayor oferta, de acuerdo con la Figura 14 (se separa en un gráfico aparte para poder observar mejor los datos de las otras ofertas de servicios turísticos) y las de alquiler de vehículos, la menor, según la Figura 13.

También se observa en la Figura 13, que la oferta de transporte acuático tiene una tendencia a la baja desde el año 1997 hasta el 2011. La oferta de empresas 


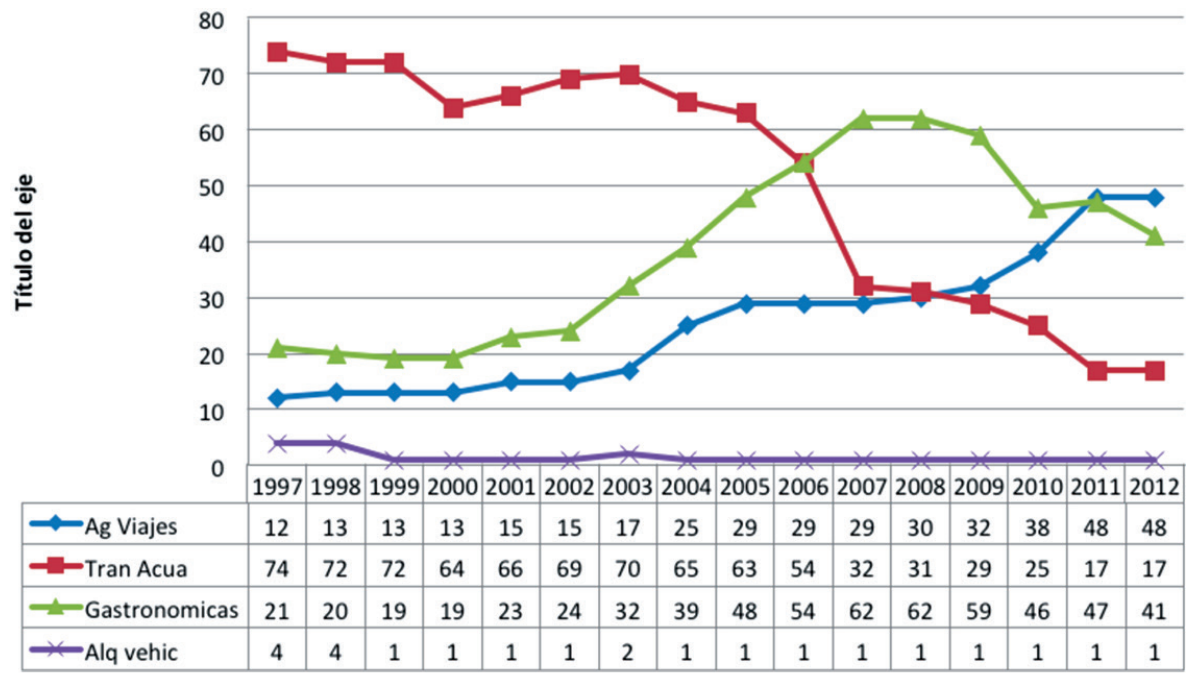

Figura 13. Empresas con declaratoria turística en Puntarenas y Guanacaste, 1997-2012.

Fuente: Elaboración propia con los datos de los Anuarios del (Instituto Costarricense de Turismo, 1988-2012).

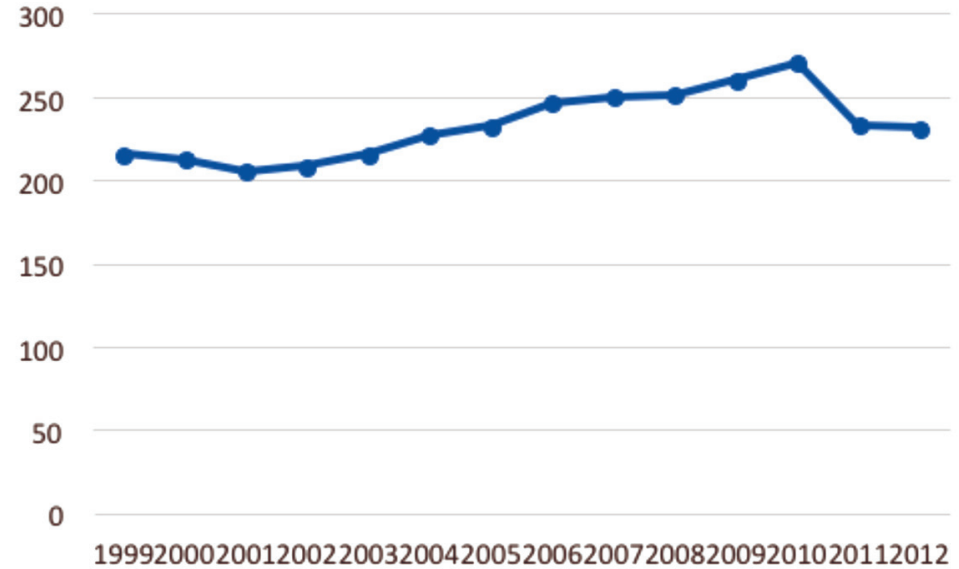

Figura 14. Empresas de hospedaje en Puntarenas y Guanacaste, 1999-2012.

Fuente: Elaboración propia con los datos de los Anuarios del (Instituto Costarricense de Turismo, 1988-2012). 
gastronómicas tiene una tendencia creciente hasta el año 2008, a partir del cual inicia el descenso. El número de agencias de viajes tiene una tendencia creciente en todo el período de estudio.

En el caso de la oferta de empresas de hospedaje, Figura 14, desde el año 1999 al 2001 la tendencia es hacia la baja, a partir de este año y hasta el año 2010 tiene un crecimiento constante y sostenido. A partir del año 2010 vuelve a disminuir.

De acuerdo con las Figuras 13 y 14, prácticamente y de manera general, el número de empresas turísticas (hospedaje, alimentación, transporte acuático, alquiler de vehículos) tienen una tendencia a la baja o de estabilidad, en los últimos años, excepto las agencias de viajes. Esto no ha afectado el ingreso de turistas extranjeros, pues contrariamente éste ha aumentado en los últimos años, según los datos representados en la Figura 1. Lo anterior está muy relacionado con el aumento de agencias de viajes.

La oferta turística de Costa Rica se ha incrementado enormemente en los últimos años a través de una gran diversidad de actividades y formas de hacer turismo. Otra clasificación que podemos asociar es la distinción de la oferta de acuerdo a las siguientes definiciones de turismo: enclave, rural comunitario, aventura y ecológico.

Las siguientes secciones detallan la oferta de actividades turísticas existentes en la región del Pacífico Costarricense, según la clasificación anterior.

Cabe observar que las actividades turísticas no se pueden encasillar en una categoría específica, es decir, se encuentra actividades que se practican en dos o más categorías de turismo de forma indistinta, por ejemplo: ecológico y turismo rural o en turismo de enclave y turismo de aventura; o en turismo de enclave, turismo ecológico y turismo rural, de manera combinada.

\section{TURISMO RURAL COMUNITARIO}

El turismo rural comunitario se compone de experiencias turísticas planificadas e integradas sosteniblemente al medio rural y desarrolladas por los pobladores locales, organizadas para beneficio de la comunidad (Actuar, 2013).

Las seis características que lo definen son:

1. Integra las riquezas naturales y la vida cotidiana de la comunidad rural.

2. Promueve las prácticas productivas sostenibles dentro de la oferta turística. 
3. La experiencia turística se adapta a la dinámica rural y preserva la peculiaridad, rusticidad, así como el ambiente acogedor y confortable que caracterizan la ruralidad del país.

4. Se sustenta en la gestión y participación local y fortalece la organización en la que participan varias familias o toda la comunidad.

5. Integra a la población local en esta actividad empresarial, distribuye equitativamente los beneficios y complementa los ingresos de las familias rurales.

6. Promueve la tenencia de la tierra por parte de los pobladores locales (Actuar, 2013).

Dentro de esta definición de turismo rural y observando las actividades turísticas que se ofrecen, se encuentra una mezcla de actividades que también se practican en el turismo ecológico y en el turismo de aventura. Lo que hace la diferencia es que este tipo de actividades son ofrecidas por organizaciones comunales y locales, en las que participan varias familias o toda la comunidad.

En este sentido se encuentran ofertas de actividades como las siguientes:

- $\quad$ Observación de aves

- Observación de flora y fauna

- $\quad$ Observación de delfines y ballenas

- $\quad$ Buceo y snorkeling

- Baño en cataratas

- $\quad$ Transporte a caballo

- Transporte en bote

- Caminatas

- $\quad$ Paseo en bicicleta

- Visita a los manglares 
- Spa natural con barro

- Observación y práctica de procesos artesanales: pesca con cuerda, extracción de moluscos, trapiche, agricultura orgánica, plantas medicinales, proceso del café

- Talleres de educación ambiental y conservación, historia y tradición

- $\quad$ Disfrute de alimentos tradicionales y cultura local

- $\quad$ Recorridos en comunidades indígenas

Se pueden encontrar ofertas de turismo rural en las tres regiones del Pacífico.

\section{TURISMO DE AVENTURA}

Turismo aventura es definido por el Decreto Ejecutivo 31095 MEIC-TUR del 31 de marzo del 2003 como "aquellas actividades recreativas que involucren un nivel de habilidades físico-deportivas con riesgo identificado y en contacto directo con la naturaleza" (Ministerio de Economía Industria y Comercio , 2003, pág. 1). Las siguientes actividades están dentro de esta categoría: "Canopy" (deslizamiento entre árboles sobre cables), "sky walk" o "sky trek" (caminata por puentes colgantes), "bungee jumping" (salto al vacío sujeto por una cuerda), "while water rafting" (balsas en ríos), buceo, "rapel" (descenso con cuerdas), escalar, ciclismo de montaña, navegación en kayak en río o mar, cabalgatas, caminatas (de uno o varios días por montañas, cuevas, cañones).

Este tipo de turismo supone un cierto riesgo, requiere de un entrenamiento o preparación mínima y un equipo apropiado para la práctica de la actividad.

El turismo de aventura tiene como objetivo principal el fomento de las actividades de aventura en la naturaleza. Consiste en visitar o alojarse en zonas donde se pueden desarrollar los llamados deportes de aventura o turismo activo.

También el turismo de aventura puede clasificarse según su dificultad: baja, moderada o alta. En los viajes de turismo de aventura se encuentra implícito el conocer lugares, su gente y su cultura de manera activa y participativa.

En la Tabla 5 se presenta un recuento de las actividades de turismo de aventura que pueden encontrarse en la región del Pacífico costarricense. 
Tabla 5

ACTIVIDADES DE TURISMO DE AVENTURA

\begin{tabular}{|c|c|c|c|}
\hline ACTIVIDAD & PACÍFICO NORTE & PACIFICO CENTRAL & PACIFICO SUR \\
\hline Canopy & $\mathrm{x}$ & $\mathrm{x}$ & $\mathrm{x}$ \\
\hline Buceo & $\mathrm{x}$ & $\mathrm{x}$ & $\mathrm{x}$ \\
\hline Pared escalada & $\mathrm{x}$ & $\mathrm{x}$ & \\
\hline Snorkeling & $\mathrm{x}$ & $\mathrm{x}$ & $\mathrm{x}$ \\
\hline Rafting & $\mathrm{x}$ & $\mathrm{x}$ & $\mathrm{x}$ \\
\hline Surf & $\mathrm{x}$ & $\mathrm{x}$ & $\mathrm{x}$ \\
\hline Kayak & & $\mathrm{x}$ & $\mathrm{x}$ \\
\hline Descenso de barrancos o cavernas & $\mathrm{x}$ & & $\mathrm{x}$ \\
\hline Escalada de árboles & & & $\mathrm{x}$ \\
\hline Rapel & & $\mathrm{x}$ & $\mathrm{x}$ \\
\hline Parapentiun & & $\mathrm{x}$ & \\
\hline Bungee & & $\mathrm{x}$ & \\
\hline Canoas & $\mathrm{x}$ & $\mathrm{x}$ & $\mathrm{x}$ \\
\hline Safary & $\mathrm{x}$ & & \\
\hline Puentes colgantes & & $\mathrm{x}$ & \\
\hline Bicicletas & $\mathrm{x}$ & $\mathrm{x}$ & \\
\hline Pesca & $\mathrm{x}$ & $\mathrm{x}$ & $\mathrm{x}$ \\
\hline Cabalgata & $\mathrm{x}$ & $\mathrm{x}$ & $\mathrm{x}$ \\
\hline Teleférico & & $\mathrm{x}$ & \\
\hline Caminatas & $\mathrm{x}$ & $\mathrm{x}$ & $\mathrm{x}$ \\
\hline
\end{tabular}

Nota: Fuente: Elaboración propia con datos de la investigación. 


\section{TURISMO ECOLÓGICO}

De acuerdo con Rojas (2006), el turismo ecológico o ecoturismo es "aquella modalidad turística ambientalmente responsable consistente en viajar a, o visitar áreas naturales relativamente sin disturbar; con el fin de disfrutar, apreciar y estudiar los atractivos naturales de dichas áreas, así como cualquier manifestación cultural (del presente y del pasado) que pueda encontrarse ahí".

La Sociedad Internacional de Ecoturismo (1990) define ecoturismo como "un viaje responsable a áreas naturales que conservan el ambiente y mejoran el bienestar de la población local". De acuerdo con (Honey, 1999, pág. 22) el ecoturismo debe seguir los siguientes siete principios, tanto para quienes operan los servicios como para quienes participan:

1. Minimizar los impactos negativos, para el ambiente y para la comunidad, que genera la actividad.

2. Construir respeto y conciencia ambiental y cultural.

3. Proporcionar experiencias positivas, tanto para los visitantes como para los anfitriones.

4. Proporcionar beneficios financieros directos para la conservación.

5. Proporcionar beneficios financieros y fortalecer la participación en la toma de decisiones de la comunidad local.

6. Crear sensibilidad hacia el clima político, ambiental y social de los países anfitriones.

7. Apoyar los derechos humanos universales y las leyes laborales.

En la Tabla 6 se muestran las actividades de turismo ecológico que se ofrecen en las tres regiones del Pacífico.

Este tipo de experiencia turística tiene la virtud de ser "un proceso que promueve la conservación, tiene bajo impacto negativo ambiental y cultural, y propicia un involucramiento activo y socioeconómicamente benéfico de las poblaciones locales" (Rojas, 2006).

Se pueden practicar en las áreas del Sistema Nacional de Conservación, las cuales se clasifican en: reservas biológicas, parques nacionales, reservas forestales, 
refugios de vida silvestre, zonas protectoras y humedales. Pero también se llevan a cabo en otras zonas públicas como playas, ríos y cataratas; o en territorios de inversión y organización privada. Además, como se puede observar, estas actividades son prácticamente las mismas que ofrecen las organizaciones que promueven el turismo rural comunitario, esto debido a que los principios y objetivos de este turismo tienen muchas coincidencias con el objetivo del turismo ecológico.

Por otro lado, es importante hacer notar que las áreas protegidas no solo son aptas para el turismo ecológico, sino que muchas actividades de turismo aventura también se dan dentro de estas zonas, tales como: surfing, snorkeling y cabalgatas en algunas playas, descenso y caminatas dentro de cavernas, entre otras.

\section{Tabla 6}

ACTIVIDADES DE TURISMO ECOLÓGICO

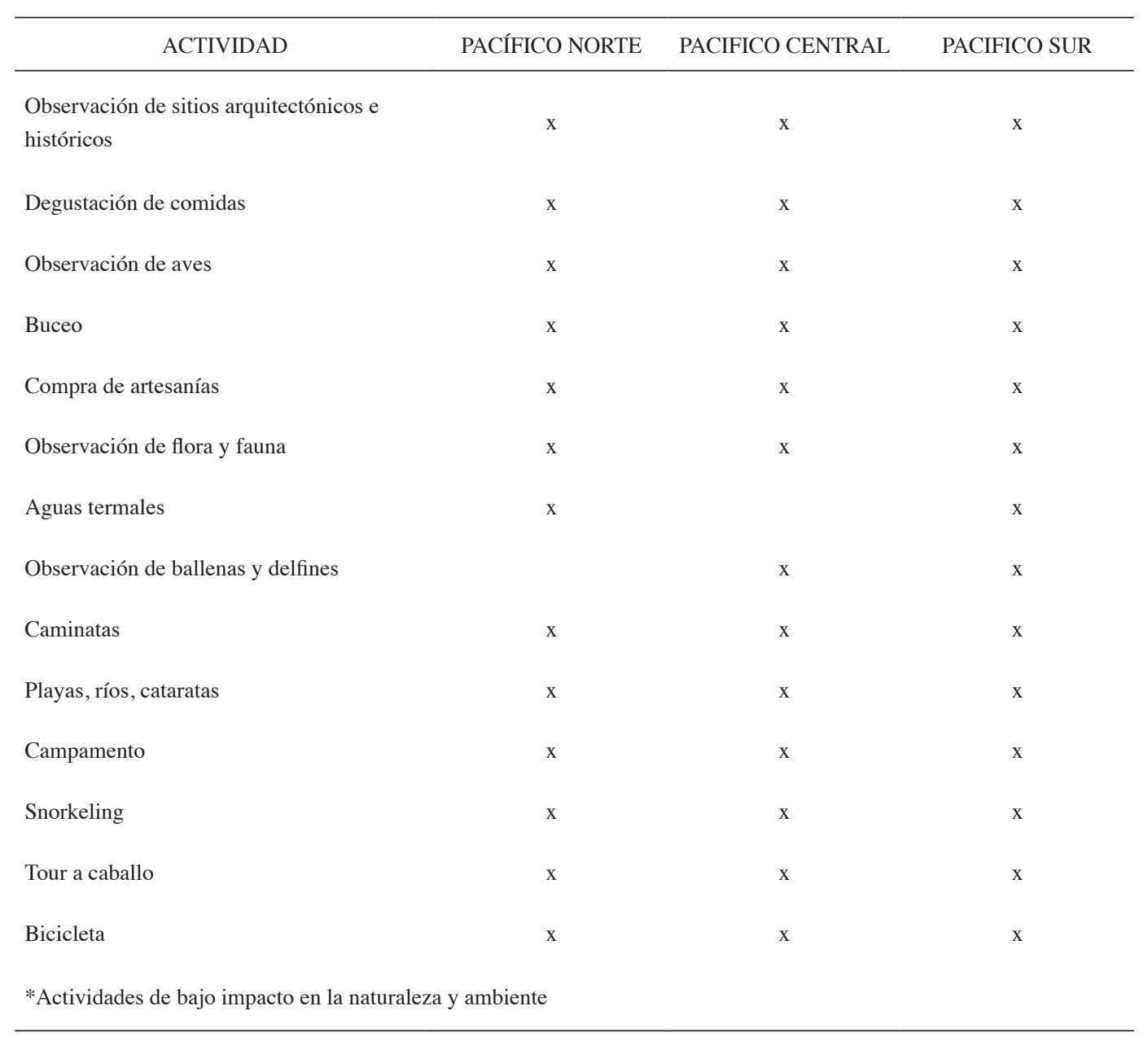

Nota: Fuente: Elaboración propia con datos de la investigación. 


\section{TURISMO DE ENCLAVE}

El modelo de "enclave" se caracteriza por el emplazamiento turístico de gran escala, dominado especialmente por el capital trasnacional turístico. Este tipo de desarrollo turístico genera una considerable cantidad de empleo, al mismo tiempo que se le atribuyen consecuencias culturales importantes como la anulación de las identidades locales. Y, en lo que respecta a sus consecuencias ambientales se le ha imputado grandes alteraciones, debido a las modificaciones en el medio natural y las altas demandas energéticas y de agua (Cordero y Van Duynen, 2002).

Costa Rica no ha escapado a este tipo de desarrollo turístico, principalmente se ha desarrollado en la zona de Guanacaste y se caracteriza por los grandes complejos turísticos o megaproyectos con enormes inversiones en infraestructura física y un diseño artificial del destino turístico (Lizano, 1998).

Este tipo de desarrollo concentra al visitante dentro de las instalaciones del hotel, se le ofrecen múltiples actividades de diversión y descanso y se le provee de todos los servicios que pueda desear o necesitar. Se ha desarrollado fuertemente en la región del Pacífico Norte, en donde se pueden contabilizar más de trece grandes proyectos de infraestructura hotelera en toda la zona de Guanacaste. En el Pacífico Central se pueden contabilizar al menos once proyectos de este tipo, sin ser exhaustivo. Estos complejos hoteleros son la base del turismo de enclave. En el Pacífico Sur los desarrollos hoteleros existentes son de menor escala y más bien solo ofrecen el servicio de alojamiento y algunos otros servicios básicos para el turista que viaja a esa zona, por lo que no se puede clasificar dentro de la oferta para el turismo de enclave, de acuerdo con la definición dada por Cordero y Van Duynen (2002).

Algunos desarrollos que favorecen el turismo de enclave se muestran en la Tabla 7.

Dentro de estos complejos turísticos, se ofrecen actividades turísticas como: kayak, cabalgata, tour en lanchas, caminatas en senderos artificiales, pesca recreativa, buceo, yet ski, etc. Es decir, se pueden encontrar las mismas ofertas de actividades dentro del complejo turístico, sin tener que salir de este espacio para contratarlas.

A diferencia del Pacífico Norte y Central, el desarrollo inmobiliario de la zona del Pacífico Sur, resultado del despertar turístico que provocó la apertura de la costanera Sur, no ha causado mayores impactos en la naturaleza, pues desde sus inicios, la mayor parte de los proyectos tenían el objetivo de ofrecer confort en armonía con el ambiente, por lo que los desarrollos fueron pequeños y no violentaron el paisaje ni el ambiente, a diferencia de los grandes proyectos del Pacífico Norte y Central (TT Argos, 2013, págs. VI-11). 


\section{Tabla 7}

HOTELES QUE FAVORECEN EL TURISMO DE ENCLAVE

PACÍFICO NORTE

PACÍFICO CENTRAL

Riu Guanacaste
Barceló Tambor
Barceló Langosta
Hilton Papagayo Resorte \& Spa
Occidental Allegro Papagayo
Riu Palace
Western Playa Conchal
Willas Sol
Villas Playa Sámara
Allegro Papagayo
Tamarindo Diriá
Flamingo Beach Resort \& Spa
Barceló Tamarindo Beach

Doble Tree Resorte Hilton Puntarenas

Terraza del Pacífico

Best Western Jaco Beach

Villa Caletas

Villa Lapas

Punta Leona

Los Sueños de Marriott

Issimo Boutique Hotel \& Spa

Arenas del Mar

Hotel The Preserve en Los Altos

Hotel San Bada

Nota: Fuente: Elaboración propia con datos de la investigación.

\section{PLAYAS CON BANDERA AZUL ECOLÓGICA.}

Por otro lado, la costa Pacífica de Costa Rica posee muchas playas, las cuales son consideradas, a nivel internacional, lugares de gran belleza escénica y han sido consideradas uno de los principales atractivos turísticos del país.

Como lo analizan Marín y Viales (2012, pág. 190), el crecimiento y desarrollo del turismo en la Costa Pacífica trajo a la par consecuencias negativas, entre ellas, la contaminación de las aguas de los ríos, mares y esteros, situación que no fue sopesada por las autoridades gubernamentales en los primeros años de desarrollo de la actividad turística.

La toma de conciencia sobre este problema llegó a partir de 1995, cuando Costa Rica inicia con el programa denominado Bandera Azul Ecológica, que consiste en otorgar certificaciones a las comunidades que logran satisfacer aspectos de la calidad del agua de mar, calidad de las playas, acceso a agua potable, tratamiento de aguas residuales, educación ambiental, seguridad y administración. Anualmente se realizan evaluaciones y diagnósticos sanitarios para mantener la certificación de las playas. 
La Bandera Azul Ecológica se establece como un galardón a los hoteles, cámaras de turismo y comunidades costeras para proteger de manera integral las playas de Costa Rica (Programa de Bandera Azul Ecológica, 2013).

Se certificaron 59 y 60 playas, en el año 2009 y 2010, respectivamente (Honey, Vargas y Durham, 2010, pág. 59). Durante el 2012, de 115 playas, un total de 90 obtuvieron Bandera Azul Ecológica. Las siguientes playas obtuvieron el certificado de Bandera Azul Ecológica en el 2012 (Soto, 2013):

5 estrellas Blanca (Garabito, Puntarenas) y Punta El Madero (Santa Cruz, Guanacaste)

4 estrellas Matapalo

3 estrellas bahía Junquillal y Manuel Antonio

2 estrellas Arenilla, Conchal y Guiones

1 estrella 82 playas (puede encontrar el listado en (Instituto Costarricense de Turismo, 2013, pág. 23A) (Instituto Costarricense de Turismo, 2013, pág. 23A)

De estas 90 playas galardonadas 71 pertenecen a la costa del Pacífico y 19 a la costa del Caribe.

Este programa se considera importante para la atracción del turista que busca el sol y la playa, pues los resultados del galardón se publican en los medios de comunicación masiva del país y se constituye en un factor determinante para que los posibles visitantes decidan ir o no a una playa determinada.

\section{SISTEMA NACIONAL DE ÁREAS DE CONSERVACIÓN (SINAC)}

El artículo 22 de la Ley de Biodiversidad $N^{\circ} 7788$, publicada en La Gaceta $\mathrm{N}^{\circ}$ 101 del 27 de mayo de 1998 crea el Sistema Nacional de Áreas de Conservación, por sus siglas SINAC (Gaceta, 1998), como un sistema de gestión y coordinación institucional, desconcentrado y participativo, con personalidad jurídica instrumental, que integra las competencias en materia forestal, vida silvestre, áreas protegidas y la protección y conservación del uso de cuencas hidrográficas y sistemas hídricos. Los objetivos primordiales de este organismo son dictar políticas, planificar y ejecutar procesos dirigidos a lograr la sostenibilidad en el manejo de los 
recursos naturales de Costa Rica. Para esto, dividió el territorio nacional en áreas de conservación dentro de los cuales se designaron áreas de protección. En la Tabla 8 se muestra la lista de áreas protegidas de la región Pacífica de Costa Rica.

Tabla 8

LISTA DE ÁREAS PROTEGIDAS DE LAS ÁREAS DE CONSERVACIÓN DE LA REGIÓN PACÍFICA

\begin{tabular}{ll}
\hline ÁREA DE CONSERVACIÓN & ÁREAS PROTEGIDAS \\
\hline
\end{tabular}

Área de Conservación de Guanacaste (ACG)
Área de Conservación Arenal Tempisque (ACAT)

Área de Conservación Tempisque (ACT)

Área de Conservación La Amistad-Pacífico (ACLAP)
Estación experimental Horizontes

Parque Nacional Rincón de la Vieja

Parque Nacional Santa Rosa

Refugio Nacional de Vida Silvestre Junquillal

Parque Nacional Guanacaste

Parque Nacional Palo Verde

Parque Nacional Volcán Tenorio

Refugio de Vida Silvestre Cipancí

Reserva biológica Lomas Barbudal

Humedal Lacustrino Río Cañas

Humedal Palustrino Corral de Piedra

Parque Nacional Barra Honda

Parque Nacional Diriá

Parque Nacional Marino Las Baulas

Refugio Nacional de Vida Silvestre Camaronal

Refugio Nacional de Vida Silvestre Ostional

Refugio Nacional de Vida Silvestre Caletas Arío

Refugio Nacional de Vida Silvestre Cipancí

Refugio Nacional de Vida Silvestre Hacienda El Viejo

Refugio Nacional de Vida Silvestre Iguanita

Refugio Nacional de Vida Silvestre Langosta

Refugio Nacional de Vida Silvestre Mata Redonda

Refugio Nacional de Vida Silvestre Mixto Conchal

Reserva Natural Absoluta Cabo Blanco

Zona Protectora Montealto

Refugio Natural Vida Silvestre Tamarindo

Parque Nacional Chirripó

Parque Nacional Tapantí Macizo de la Muerte

Parque Internacional La Amistad

Reserva Forestal Río Macho

Zona Protectora Las Tablas

Zona Protectora Río Navarro-Río Sombrero 


\begin{tabular}{ll}
\hline \multicolumn{1}{c}{ ÁREA DE CONSERVACIÓN } & \multicolumn{1}{c}{ ÁREAS PROTEGIDAS } \\
\hline Área de Conservación Marina Isla del Coco (ACMIC) & $\begin{array}{l}\text { Parque Nacional Isla del Coco } \\
\text { Área Marina de Manejo de Montes Submarinos }\end{array}$ \\
& \\
& Parque Nacional Carara \\
& Parque Nacional La Cangreja \\
Área de Conservación Pacífico Central (ACOPAC) & Parque Nacional Manuel Antonio \\
& Parque Nacional Los Quetzales \\
& Refugio Nacional de Vida Silvestre Isla San Lucas \\
& Refugio de Vida Silvestre Playa Hermosa Punta Mala \\
& \\
& Humedal Nacional Térraba Sierpe \\
& Parque Nacional Corcovado \\
& Parque Nacional Marino Ballena \\
Área de Conservación OSA (ACOSA) & Parque Nacional Piedras Blancas \\
& Refugio Nacional de Fauna Silvestre Golfito \\
& Reserva Biológica Isla del Caño \\
& Reserva Forestal Golfo Dulce \\
\hline
\end{tabular}

Nota: Fuente: Elaboración propia con datos del (Sistema Nacional de Áreas de Conservación, 2013).

Las áreas protegidas corresponden a un total de 1.354.488 hectáreas del territorio nacional, y abarcan el 26,54\% (Pavlotzky y Rojas, 2012, pág. 4). El territorio nacional está dividido en 11 áreas de conservación de las cuales 7 se encuentran en el Pacífico costarricense. La Tabla 8 muestra el detalle de las áreas protegidas de acuerdo con las áreas de conservación a las que pertenecen.

En la Figura 15 se muestra la distribución de áreas silvestres protegidas que se encuentran en el Pacífico costarricense, por categoría de manejo. En el gráfico se representa el predominio de los parques nacionales y los refugios nacionales de vida silvestre. La extensión total de estas áreas protegidas en el Pacífico suma 429.182,91 hectáreas del territorio nacional, que corresponden al 36\% del total de las áreas protegidas a nivel nacional. En esta suma no se contabilizan las áreas del territorio marino protegido, el cual corresponde a 1.501 .485 hectáreas que equivale al 49,54\% de las aguas territoriales del país (Pavlotzky y Rojas, 2012, pág. 55).

Todas estas áreas protegidas conforman un conjunto de oferta basada en la biodiversidad del país, que es aprovechado por las diversas empresas turísticas para fomentar el turismo ecológico, el turismo rural y el turismo de aventura, como se mencionó en apartados anteriores.

Por otro lado, y como se puede observar en las Figuras 6 y 7, la afluencia de visitantes a las áreas de conservación del Pacífico tiene un comportamiento creciente en el período que va del 2002 al 2012, con solo una disminución en el año 
2005, pero superando incluso a las áreas del Valle Central a partir del año 2006. Lo anterior demuestra el cambio de los gustos de los turistas hacia zonas con bellezas naturales, y ya no solo la tendencia a los destinos de "sol y playa" como ocurría en las primeras décadas del siglo XX.

A pesar de lo anterior, las distintas regiones del Pacífico tienen diferencias en el número de visitantes que reciben, como se muestra en la Figura 8, en el cual se evidencia que las áreas más visitadas son las del Pacífico Central.

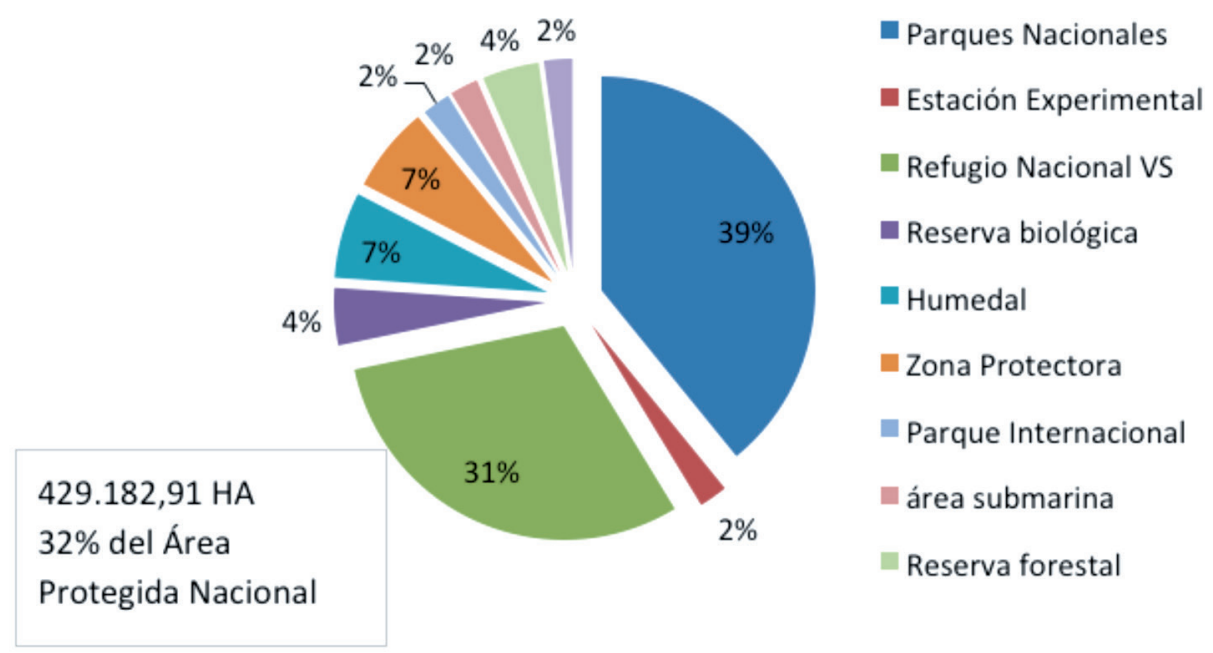

Figura 15. Áreas silvestres protegidas por categoría de manejo, Pacífico de Costa Rica. Fuente: Elaboración propia con datos del (Sistema Nacional de Áreas de Conservación, 2013) (Sistema Nacional de Áreas de Conservación, 2013).

\section{CONCLUSIONES}

En este recorrido a lo largo del Pacífico costarricense se observan gran cantidad y variedad de ofertas de actividades turísticas, así como de servicios turísticos, que proporcionan al turista las condiciones necesarias para el disfrute, el descanso y la recreación.

Los datos registrados de 1997 al 2012 para el Pacífico (Guanacaste y Puntarenas) informan de manera general y para todo el período, que el número de empresas turísticas de hospedaje, alimentación, agencias de viaje y empresas gastronómicas tienen una tendencia a la alza, aunque registran una leve baja en algunos años. Solamente la oferta de transporte acuático y alquiler de vehículos tienen una disminución en el período de estudio. Es importante tomar en cuenta que esta información sólo se refiere a empresas con declaratoria turística.

De la clasificación de las actividades turísticas que se analizaron, a saber, enclave, ecológico, aventura y rural comunitario, se destaca que dichas actividades 
no pueden ser encasilladas únicamente en una categoría de éstas. Encontramos actividades que se ofrecen en varias de las categorías de turismo establecidas. Por otro lado, la oferta de este tipo de programas es similar a lo largo de la costa Pacífica, a excepción del Pacífico Sur, donde no se pueden catalogar comercios dentro del turismo de enclave.

El país ha realizado grandes esfuerzos para conservar extensos territorios en su medio natural. De las regiones en que está dividido el país, según el Sistema Nacional de Conservación, la del Pacífico registra un crecimiento constante de la afluencia de visitantes desde al año 2005 al 2012, superando, incluso, la del Valle Central (segunda en nivel de visitas), que para el 2008 cae drásticamente. Lo que muestra que hay un mayor gusto por recorrer las zonas naturales fuera de la Meseta Central.

Los datos también muestran que la mayoría de los visitantes extranjeros buscan la recreación en zonas con belleza natural y que el principal atractivo son las playas del país. Sin embargo, se puede observar un aumento de otras actividades turísticas como: observación de flora y fauna, caminatas, canopy, aguas termales, visita a volcanes, entre otras.

La extensión e irregularidad de la costa Pacífica favorece la biodiversidad y los espacios naturales para ser disfrutados por el turista; esto ha sido una gran ventaja que posee el país y que se ha constituido en el sello de distinción que el Gobierno ha explotado para promover el desarrollo del turismo.

Se reconoce el desarrollo vertiginoso que ha tenido el turismo en el Pacífico costarricense durante la última mitad del siglo XX y principios del siglo XXI, el cual es producto de la política estatal que ha incentivado y promovido las inversiones en la región, principalmente en la zona del Pacífico Norte y Central.

Como puede observarse en el estudio, también en la zona norte del Pacífico, principalmente, se encuentran grandes inversiones infraestructurales hoteleras que se enmarcan dentro del turismo enclave, el cual ha sido muy criticado debido a los altos impactos en el ambiente y la cultura local. El Estado debe controlar este tipo de proyectos, con el fin de minimizar estos impactos y más bien convertirlos en ejemplos de turismo sostenible, socialmente responsable y basado en las fortalezas del país (como recursos, capacidades y atracciones naturales locales); y que tiene mayores posibilidades de una mejor distribución de ingresos a sectores vulnerables; a diferencia de las propuestas para el establecimiento de turismo de enclave, que depende grandemente del turismo extranjero, altamente vulnerable a la recesión económica global, con altos impactos ambientales y poco derrame económico a sectores vulnerables.

Sin embargo, el desarrollo de un turismo sostenible presenta retos importantes para que haya un impacto positivo en las comunidades, en aspectos como: educación, organización comunal, apoyo económico, técnico y financiero de instituciones públicas, mejora de infraestructura, entre otros. Blanco (2012) documenta la 
experiencia desarrollada en dos comunidades del norte de Guanacaste, en las que hubo reconversión productiva de la agricultura hacia el turismo, experiencia no ha sido tan exitosa como se esperaba.

En uno de los apartados de este trabajo se mostró el progreso infraestructural para asentamientos humanos y turísticos de algunas localidades, en tres momentos distintos: 1980,1998 y 2005, cuyo resultado demuestra que Puntarenas-Caldera, Playa Grande-Tamarindo y Herradura-Jacó son las zonas que tienen mayor número de hectáreas desarrolladas durante el período en estudio. Sin embargo, para los años 2006 y 2007 las mayores inversiones extranjeras se concentraron en Golfito y Osa. Por otra parte, durante los años 2005 al 2007, las inversiones extranjeras de bienes raíces se concentraron mayormente en la costa Pacífica, las cuales no necesariamente correspondían a proyectos hoteleros, sino a la construcción de casas para vacacionar, condominios y villas, sitios que compiten con la oferta hotelera y además luchan por recursos con las comunidades locales.

El Programa Bandera Azul Ecológica es una importante propuesta que se debe promover de manera más fuerte y efectiva, de tal manera que pueda incluir a más comunidades para su certificación.

El estudio de Villalobos, Galdeano y Tolón (2009) concluye con recomendaciones, las cuales fueron mencionadas en este estudio, para impulsar una estrategia que permita incentivar el turismo naturaleza.

En cuanto al turismo de cruceros, observamos que el ingreso de turistas por el puerto del Pacífico ha disminuido, al mismo tiempo que ha aumentado en el Caribe. Esto ocurre a partir del año 2001. Sin embargo, a partir del 2011, el ingreso de turistas al puerto del Pacífico supera al puerto del Caribe. Esto último puede ser producto de la problemática generada por las propuestas del Gobierno de construir un nuevo puerto en el Caribe, situación que ha generado mucha controversia entre los grupos de trabajadores y fuerzas vivas de la comunidad de Limón.

Por otro lado, el ingreso de turistas al puerto del Pacífico, provenientes de cruceros, no ha generado los beneficios económicos esperados para los pobladores de las comunidades cercanas, debido a que los visitantes llegan con paquetes turísticos comprados previamente, que los llevan a destinos fuera de la ciudad. A pesar de ello, y de acuerdo con Mora (2013, pág. 109) hay un incremento moderado de ingreso para los pequeños comerciantes, principalmente para los que venden productos como licores, tabaco y recuerdos de viaje.

De acuerdo con Honey, Vargas y Durham (2010, pág. 101) no es recomendable expandir el turismo de cruceros de alto volumen en Puntarenas y Caldera, pues no está brindando los beneficios a estas regiones, ni al país como un todo. Ellos recomiendan dejar el turismo de masa de cruceros en la zona Caribe, como parte de un producto turístico general del país, y en el Pacífico enfocarse a cruceros 
pequeños (de menos de 250 pasajeros) que proporcionan más beneficios por pasajero a la región y tienen un menor impacto social y ambiental. Además, recomiendan que se negocie un importe más alto por pasajero y otras tarifas y servicios; así como dar un mayor acceso a vendedores y negocios locales para ofrecer bienes y servicios en tierra a los usuarios de los cruceros.

A pesar del aumento de turistas que visitan las zonas del Pacífico, se encuentran todavía zonas rurales con bajos índices de desarrollo humano, principalmente en las regiones del Pacífico Norte y Pacífico Sur del país, lo que muestra todavía la falta de un ordenamiento y una mejor distribución, planeación o encadenamiento de las actividades turísticas que permitan irradiar los beneficios a toda la población rural de las costas. De acuerdo con Honey, Vargas y Durham (2010, pág. 103), el turismo de enclave (como lo hemos llamado en este estudio) y de cruceros ha traído beneficios económicos inferiores al país, en contraste con el turismo relacionado con actividades naturales y culturales que tiene impactos más positivos en la economía local, por lo que el país debería fomentar este último.

Por otro lado, cabe mencionar que los turistas pueden estar motivados por atractivos concretos, pero que han de desplazarse a otros lugares donde existen otros sitios de interés, así como condiciones de alojamiento, accesibilidad y ofertas complementarias, etc., que pueden, en su caso, llegar a frustrar la elección, si estos otros factores actúan negativamente en el destino elegido (Lepe y Pardellas, 2008, pág. 162). Dado lo anterior, el desarrollo de la oferta de actividades turísticas debe ir paralela al mejoramiento de las condiciones adecuadas para la atención del turista, esto es: vías de comunicación vial, servicios de transporte, hospedaje, alimentación, seguridad, ornato, etc. En el caso de la región Pacífica, se observan grandes diferencias en la oferta de servicios al turista entre el Pacífico Norte y Central con respecto al Pacífico Sur, lo que puede influir en la baja demanda que se presenta en esta última.

Finalmente, las campañas promocionales que ha realizado el Instituto Costarricense de Turismo en los últimos años, para posicionar internacionalmente la imagen de una Costa Rica "verde" y promover el turismo naturaleza, el ecológico o sostenible, requieren un enfoque diferenciado para las distintas regiones, de acuerdo a sus singularidades, según lo indican Lepe y Pardellas (2008, pág. 165), para atraer visitantes que buscan esas particularidades, considerando además que la mayoría de los turistas internacionales llegan al país por razones de ocio y recreación.

Es importante mencionar otros factores que pueden entrar en juego como: niveles de educación, fuerza institucional y gastos sociales que limitan la retribución del desarrollo del turismo (Croes, 2012, pág. 58), por lo que el Estado debe revisar su política pública y su estrategia en materia turismo, pues ha sido exitoso en la reducción de la pobreza, pero no ha sido capaz de convertir las mejoras en 
los indicadores de educación y salud en ganancias productivas, incluyendo las generadas por el turismo. "Los niveles de desigualdad en Costa Rica se han incrementado desde la década de los noventas y los índices de pobreza se han estancado a pesar del crecimiento económico en general y desempeño turístico en particular" (Croes, 2012, pág. 56).

La oferta que se ha descrito se basa principalmente en el potencial aprovechamiento de la naturaleza y la biodiversidad que posee la Costa Pacífica, que como se describió, incluye espacios naturales como las playas, montañas, ríos, cavernas, bosques, áreas protegidas de conservación; en los cuales se ofrecen diferentes actividades como cabalgatas, caminatas, observación, pesca, buceo, canopy, etc. Sin embargo, en este estudio no se ha considerado la oferta de tipo cultural y de costumbres locales, ni otras como el turismo salud y turismo negocio, conceptos nuevos que han surgido recientemente. Aunque de alguna forma, el turismo rural comunitario propone actividades de tipo cultural comunitario, existen otras que forman parte de la oferta periódica anual de las propias comunidades, la cual incluye actividades relacionadas a celebraciones específicas, como los festejos cívicos, las ferias y festivales, entre otras. En el caso concreto de Puntarenas Centro se encuentran: los carnavales, las fiestas de la Virgen del Mar, la maratón Sol y Arena, la Feria Gastronómica, la elección de la Señorita del Pacífico, y en los últimos años, las actividades deportivas competitivas como competencias de volibol de playa, ciclismo, futbol, etc. (Chen \& García, 2007, pág. 126). Todas estos eventos representan esfuerzos comunitarios y de actores locales para mantener o reactivar la economía de la región, pero que actualmente solo atraen al turismo nacional, principalmente.

Por último, queda pendiente el análisis de los impactos sociales, ambientales y económicos de las inversiones de los desarrollos turísticos, que incluyen los asociados a la construcción de infraestructura, los empleos generados de calidad y a largo plazo, el desarrollo del comercio afín en las comunidades, los trabajos informales (venta de artesanías, frutas, etc.), educación, la presión sobre los recursos requeridos, el manejo de desechos y la contaminación, entre otros.

\section{REFERENCIAS}

Actuar. (2013). Una nueva forma de viajar: turismo rural comunitario. Recuperado de: www. actuarcostarica.com/app/cms/www/index.php?id_menu=109

Barquero, M. (2013, 2 de Setiembre). País conserva ventaja en atracción de turistas. La Nación, p. 29A. 
Blanco, E. (2012). Reconversión productiva, turismo y condiciones de vida de familias campesinas en dos comunidades del norte de Guanacaste: Las Lilas en Liberia y Argendora en La Cruz. Revista Diálogos, Volumen Especial en homenaje a Bernard Vincent, 289-299.

Brenes, C. (2013, 20 de Marzo). ICT relanza campaña Vamos a Turistear 2013 con inversión de \$715.000. EF El Financiero. Disponible en : www.elfinancierocr.com

Chen, S. (2013). Desarrollo del turismo en el Pacífico costarricense: Análisis comparativo por zonas y por tipos de servicios turísticos 1988-2009. Revista Reflexiones, 92 (2), 65-78.

Chen, S., y García, K. (2007). Puntarenas y el turismo: ¿Qué ha pasado con la Perla del Pacífico? Revista Intersedes, 8 (15), 109-131.

Chen, S., y García, K. (2010). Percepción del impacto del turismo en El Roble 2 de Puntarenas, Costa Rica. Revista Reflexiones, 89 (2), 27-38.

Clare, P. (2005). El desarrollo del banano y la palma aceitera en el Pacífico costarricense desde la perspectiva de la ecología histórica. Revista Diálogos, 6 (1), 308-346.

Cordero, A., y Van Duynen, L. (2002). Turismo sostenible en Costa Rica: El caso de Quepos-Manuel Antonio. Cuadernos de Ciencias Sociales (123), 37-54.

Croes, R. (2012). Una exploración del potencial del turismo en la lucha contra la pobreza en América Latina. Revista Diálogos, Especial en homenaje a Bernard Vincent, 43-63.

Honey, M. (1999). Ecotourism and Sustainable Development: Who Owns Paradise? Estados Unidos: Island Press.

Honey, M., Vargas, E. y Durham, W. (2010). Impacto del turismo relacionado con el desarrollo de la costa Pacífica de Costa Rica. Estados Unidos: Universidad de Stanford y Washington DC. CREST.

Instituto Costarricense de Turismo.(1988-2012).Anuario.Costa Rica: Instituto Costarricense de Turismo.

Instituto Costarricense de Turismo. (2010). Resumen Ejecutivo del Plan Nacional de Turismo Sostenible de Costa Rica 2010-2016. Costa Rica: Instituto Costarricense de Turismo.

Instituto Costarricense de Turismo. (2013,15 de abril). El Instituto Costarricense de Turismo reconoce el esfuerzo de los 90 comités BAE, categoría playas, por el galardón obtenido. La Nación, p. 23 A. 
Istmo lanza plan conjunto de turismo (2013, 18 de abril). La Nación, p. 19A.

Jara, J. (2012). Perez Zeledón.net. ICT presenta plan de desarrollo turístico para el Pacífico Sur Recuperado de: http://www.perezzeledon.net/1312/ict-presenta-plan-de-desarrollo-turistico-para-el-pacifico-sur/

Lepe, I., y Pardellas, X. (2008). Un modelo de análisis de destinos turísticos: los cantones de Golfito y Limón de Costa Rica. Revista Intersedes, IX (16), 148-167.

Ley 7788 de Biodiversidad. (1998, 27 de mayo). La Gaceta No.101. Costa Rica: Gobierno de la República.

Lizano, R. (1998). Ecoturismo como modelo de desarrollo. Recuperado de: www.una.ac.cr/ambi/ Ambien-Tico/98/lizano.htm

Marín, J. y Viales, R. (2012). Turismo y ambiente en la "Perla” del Pacífico. Una relación de ansias y desencuentros. 1946-1980. Revista Electrónica de Historia Diálogos, No. Especial, 151-205.

Ministerio de Economía Industria y Comercio . (2003, 31 de Marzo). Decreto Ejecutivo No.31095 MEIC-S-TUR Reglamento para la operación de las actividades de turismo aventura. La Gaceta No. 63. Costa Rica: Gobierno de la República.

Mora, L. (2013). El impacto social y económico generado por el turismo de los cruceros que visitan la ciudad de Puntarenas. Revista Electrónica Diálogos, Volumen Especial,91-111.

Pavlotzky, B. y Rojas, G. (2010). SINAC en números: Informe Anual Estadístico SEMEC 2010. Costa Rica: Sistema Nacional de Áreas de Conservación.

Pavlotzky, B. y Rojas, G. (2012). SINAC en números: Informe Anual Estadísticas SEMEC 2012. Costa Rica: Sistema Nacional de Áreas de Conservación.

Pavlotzky, B. y Rojas, G. (2013). SINAC en números: Informe Anual Estadísticas SEMEC 2012. Costa Rica: Sistema Nacional de Áreas de Conservación.

Pavlotzky, B., \& Rojas, G. (2011). SINAC en números: Informe Anual Estadistico SEMEC 2011. Costa Rica: Sistema Nacional de Áreas de Conservación.

Programa de Bandera Azul Ecológica. (2013). Playas de Costa Rica. Recuperado de: http://playascostarica.info/programa-bandera-azul-ecologica/ 
Rojas, E. (2006). Planificación, respeto y coherencia, de la mano con el ecoturismo. Recuperado de: www.ucr.ac.cr/mostrar_noticia.php?ID=669

Rojas, E. (2006). Planificación, respeto y coherencia, de la mano con el ecoturismo. Recuperado de: Universidad de Costa Rica, Noticias: http://www.ucr.ac.cr/noticias/2006/11/03/planificacion-respeto-y-coherencia-de-la-mano-con-el-ecoturismo.html

Sistema Nacional de Áreas de Conservación. (2011). Visitantes a las áreas protegidas según unidad de planeamiento. Costa Rica: Sistema Nacional de Conservación, Gerencia de Áreas Silvestres Protegidas.

Sistema Nacional de Áreas de Conservación. (2013). Áreas de Conservación. Recuperado de: www. sinac.go.cr/AC/Paginas/default.aspx

Soto, M. (2013, 10 de abril). Bandera Azul Ecológica entregó galardones a playas más limpias. La Nación. Disponible en: http://www.nacion.com/etiqueta/bandera_azul_ecologica/

Summa. (2012). Lanzan campaña de turismo regional "Descubre Centroamérica". Revista Electrónica Summa. Disponible en: http://www.revistasumma.com/revista-digital

The Internacional Ecotourism Society. (1990). Ecoturismo. Recuperado de: www.ecotourism.org/ what-is-ecotourism

TT Argos. (2013). Dinámica territorial del desarrollo turístico costero: Unidad Turística del Pacífico Sur. Estados Unidos: Universidad de Stanford y Washington DC. CREST.

Vargas, J. (2003). Crecimiento y desarrollo de la infraestructura turística de la Fortuna de San Carlos, Alajuela 1972-2002. Reflexiones, 82 (1), 1-19.

Villalobos, D., Galdeano, E. y Tolón, A. (2009). Demanda turística internacional por turismo naturaleza en Costa Rica: indicadores sociodemográficos y de condición de viaje. Revista Ciencias Económicas, 27 (2), 75-103.

\section{ACERCA DE LA AUTORA}

Susan Chen Mok: Profesora, investigadora, catedrática de la Sede del Pacífico de la Universidad de Costa Rica. Puntarenas. Email: susan.chen@ucr.ac.cr. 